\title{
Region-specific blood-brain barrier transporter changes leads to increased sensitivity to amisulpride in Alzheimer's disease
}

Gayathri Nair Sekhar ${ }^{1}$, Alice L. Fleckney', Sevda Tomova Boyanova ${ }^{1}$, Huzefa Rupawala', Rachel Lo ${ }^{1}$, Hao Wang ${ }^{1}$, Doaa B. Farag ${ }^{1,2}$, Khondaker Miraz Rahman', Martin Broadstock ${ }^{3,4}$, Suzanne Reeves ${ }^{5}$ and Sarah Ann Thomas ${ }^{1 *}$ (D)

\begin{abstract}
Background: Research into amisulpride use in Alzheimer's disease (AD) implicates blood-brain barrier (BBB) dysfunction in antipsychotic sensitivity. Research into BBB transporters has been mainly directed towards the ABC superfamily, however, solute carrier (SLC) function in AD has not been widely studied. This study tests the hypothesis that transporters for organic cations contribute to the BBB delivery of the antipsychotics (amisulpride and haloperidol) and is disrupted in AD.
\end{abstract}

Methods: The accumulation of $\left[{ }^{3} \mathrm{H}\right]$ amisulpride (3.7-7.7 nM) and $\left[{ }^{3} \mathrm{H}\right]$ haloperidol (10 nM) in human (hCMEC/D3) and mouse (bEnd.3) brain endothelial cell lines was explored. Computational approaches examined molecular level interactions of both drugs with the SLC transporters [organic cation transporter 1 (OCT1), plasma membrane monoamine transporter (PMAT) and multi-drug and toxic compound extrusion proteins (MATE1)] and amisulpride with the ABC transporter (P-glycoprotein). The distribution of $\left[{ }^{3} \mathrm{H}\right]$ amisulpride in wildtype and $3 \times$ transgenic AD mice was examined using in situ brain perfusion experiments. Western blots determined transporter expression in mouse and human brain capillaries .

Results: In vitro BBB and in silico transporter studies indicated that $\left[{ }^{3} \mathrm{H}\right]$ amisulpride and $\left[{ }^{3} \mathrm{H}\right]$ haloperidol were transported by the influx transporter, OCT1, and efflux transporters MATE1 and PMAT. Amisulpride did not have a strong interaction with OCTN1, OCTN2, P-gp, BCRP or MRP and could not be described as a substrate for these transporters. Amisulpride brain uptake was increased in AD mice compared to wildtype mice, but vascular space was unaffected. There were no measurable changes in the expression of MATE1, MATE2, PMAT OCT1, OCT2, OCT3, OCTN1, OCTN2 and P-gp in capillaries isolated from whole brain homogenates from the AD mice compared to wildtype mice. Although, PMAT and MATE1 expression was reduced in capillaries obtained from specific human brain regions (i.e. putamen and caudate) from AD cases (Braak stage $\mathrm{V}-\mathrm{VI}$ ) compared to age matched controls (Braak stage 0-II).

Conclusions: Together our research indicates that the increased sensitivity of individuals with Alzheimer's to amisulpride is related to previously unreported changes in function and expression of SLC transporters at the BBB (in particular PMAT and MATE1). Dose adjustments may be required for drugs that are substrates of these transporters when prescribing for individuals with AD.

Keywords: Amisulpride, MATE1, PMAT, OCT1, Blood-brain barrier, Alzheimer's

*Correspondence: sarah.thomas@kcl.ac.uk

${ }^{1}$ Faculty of Life Sciences and Medicine, School of Cancer and Pharmaceutical Sciences, King's College London, Franklin-Wilkins Building, 150 Stamford Street, Waterloo, London SE1 9NH, UK Full list of author information is available at the end of the article

\section{Background}

Antipsychotic drugs are associated with significant harm in older people, particularly those with dementia who are more susceptible to antipsychotic drug related morbidity

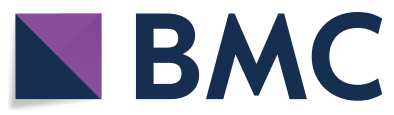

(c) The Author(s) 2019. This article is licensed under a Creative Commons Attribution 4.0 International License, which permits use, sharing, adaptation, distribution and reproduction in any medium or format, as long as you give appropriate credit to the original author(s) and the source, provide a link to the Creative Commons licence, and indicate if changes were made. The images or other third party material in this article are included in the article's Creative Commons licence, unless indicated otherwise in a credit line to the material. If material is not included in the article's Creative Commons licence and your intended use is not permitted by statutory regulation or exceeds the permitted use, you will need to obtain permission directly from the copyright holder. To view a copy of this licence, visit http://creativeco mmons.org/licenses/by/4.0/. The Creative Commons Public Domain Dedication waiver (http://creativecommons.org/publicdomain/ zero/1.0/) applies to the data made available in this article, unless otherwise stated in a credit line to the data. 
(parkinsonism, postural hypotension, stroke) and mortality than other diagnostic groups $[1,2]$. This has led to restrictions on the national health service (NHS) use of this class of drugs in the pharmacological management of psychosis and agitation in dementia. Emerging evidence from research into amisulpride use in older people with Alzheimer's disease (AD) psychosis suggests that bloodbrain barrier (BBB) dysfunction may be an important contributor to this heightened sensitivity $[3,4]$.

Amisulpride is a benzamide derivative, second generation antipsychotic drug, used to treat schizophrenia [5] and a drug for which the optimal dose (400-800 mg/ day), blood concentration (100-319 $\mathrm{ng} / \mathrm{ml}$ ) and striatal dopamine D2/3 receptor occupancy range to avoid nonresponse and parkinsonism (40-70\%) are well established in young adults with schizophrenia [6-8]. Despite being highly selective for dopamine $\mathrm{D} 2 / 3$ receptors [in vitro $\left(\mathrm{K}_{\mathrm{i}}=2.8 \mathrm{nM}\right)$ and $\mathrm{D} 3\left(\mathrm{~K}_{\mathrm{i}}=3.2 \mathrm{nM}\right)$ ] amisulpride has a low propensity to induce parkinsonism, due to its poor BBB penetration and mesolimbic selectivity [9]. In an open treatment study which used amisulpride use in older people with $\mathrm{AD}$ psychosis and very late-onset ( $>60$ years) schizophrenia-like psychosis (VLOSLP), treatment response and parkinsonism occurred at very low doses (25-75 mg/day AD, 50-100 mg/day VLOSLP), and at correspondingly low blood drug concentrations (40$100 \mathrm{ng} / \mathrm{ml} \mathrm{AD,} \mathrm{40-169} \mathrm{ng} / \mathrm{ml}$ VLOSLP) due to higher than anticipated striatal dopamine D2/3 receptor occupancies (caudate occupancy, steady state treatment, $50 \mathrm{mg} /$ day amisulpride; 41-83\% AD, 41-59\% VLOSLP) [3, 10-12]. These findings strongly implicate age and AD-specific changes in central pharmacokinetics in antipsychotic drug sensitivity, particularly at the $\mathrm{BBB}$, which controls drug entry through the expression of transporters [13]. Furthermore, they suggest that amisulpride $[14,15]$ is a sufficiently sensitive tool with which to probe $\mathrm{BBB}$ functionality.

The majority of research into $\mathrm{BBB}$ transporters has been directed towards the ABC superfamily, which are ATPdependent efflux transporters such as P-glycoprotein (P-gp) [16], whose action is compromised in age [17], and more markedly so in $\mathrm{AD}$ [18-21]. It has been suggested that amisulpride is a weak P-gp substrate [22, 23], but the importance of P-gp relative to other transporters, especially members of the SLC superfamily, remains unclear. Amisulpride is predominately positively charged (98.9\%) at physiological $\mathrm{pH}$ (pKa 9.37), and is likely a substrate for the organic cation transporters (OCT) and organic cation transporters novel (OCTN); as observed using the immortalized human cerebral microvessel endothelial cell line (hCMEC/D3) [14]. However, it is also possible that other SLC transporters of organic cations, such as plasma membrane monoamine transporter (PMAT) and multidrug and toxic compound extrusion proteins (MATEs), are involved. Haloperidol, a first generation antipsychotic drug which is highly selective for D2 receptors [24], was chosen as a clinically relevant comparator, as it is a positively charged molecule at pH7.4 and a OCT1 substrate and inhibitor $[25,26]$ and likely to utilize similar transporters to amisulpride to cross the BBB. Although the drug is no longer used as a first line treatment for psychosis, due to its propensity to cause parkinsonism, it is used at very low doses in the treatment of delirium, which most commonly occurs in those aged over 65 years and with an underlying cognitive impairment (https://www. nice.org.uk/, accessed 15.11.2019). The drug is also extensively used in palliative care and, as a result, is one of the 20 drugs on the WHO list of essential medications.

This study tested the hypothesis that there was an interaction between amisulpride and influx and/or efflux transporters at the BBB which was relevant from a pharmacodynamic perspective by:

1. identifying the transporter involved in the CNS distribution of amisulpride and haloperidol, by examining their kinetic characteristics and inhibitor sensitivity at the human and mouse BBB in vitro.

2. confirming the molecular level interactions of amisulpride and haloperidol with the selected BBB transporters using an in silico computational approach.

3. establishing whether amisulpride access to the CNS is increased in transgenic $\mathrm{AD}$ mice, which harbour the human amyloid precursor protein (APP)-Swedish mutation (KM670/671NL), tau mutation (P301L), and presenilin-1 mutation (M146V) compared to wildtype mice.

4. investigating transporter expression in human (and mouse) brain endothelium from age-matched postmortem AD and healthy aged controls.

5. Examining the type of medications prescribed to individuals with $\mathrm{AD}$ and age matched controls.

Overall $\mathrm{BBB}$ dysfunction in the $\mathrm{AD}$ process and its potential impact on drug delivery in particular on antipsychotic medication will be explored (Fig. 1). The results can also be used to inform further studies [27]. Abstracts of this work have been presented [28, 29].

\section{Materials and methods Materials}

[O-methyl- ${ }^{3} \mathrm{H}$ ]amisulpride (MW374.8; $\quad$ specific activity $77 \mathrm{Ci} / \mathrm{mmol}$; $97 \%$ radiochemical purity) was tritiated (TRQ41291 Quotient, UK). $\left[{ }^{3} \mathrm{H}(\mathrm{G})\right]$ haloperidol (MW375.9; specific activity, $20 \mathrm{Ci} / \mathrm{mmol}$; $99 \%$ radiochemical purity: cat\# ART1729) was purchased from American Radiolabelled Chemicals Inc, St. Louis, Missouri, USA. $\left[{ }^{14} \mathrm{C}(\mathrm{U})\right]$ sucrose (MW359.48; specific activity $536 \mathrm{mCi} /$ 


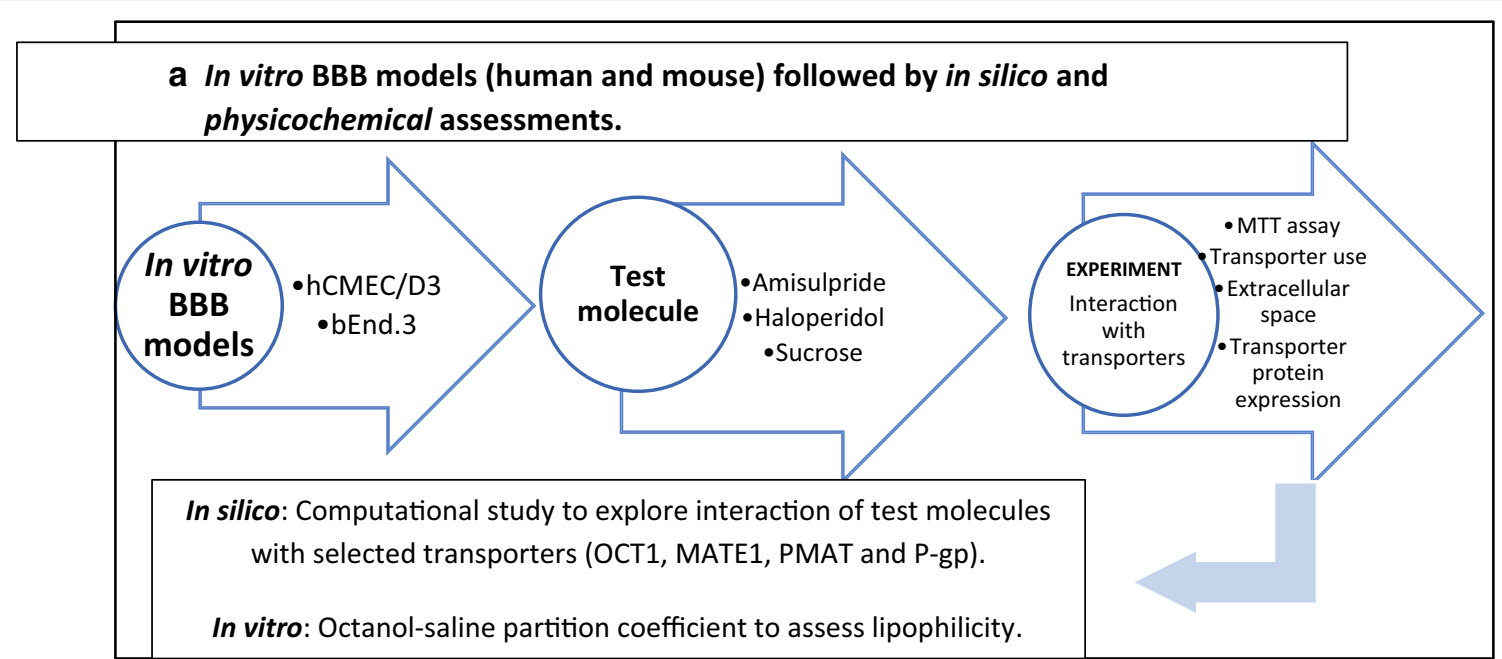

b In vivo BBB studies in wild type and transgenic mice.
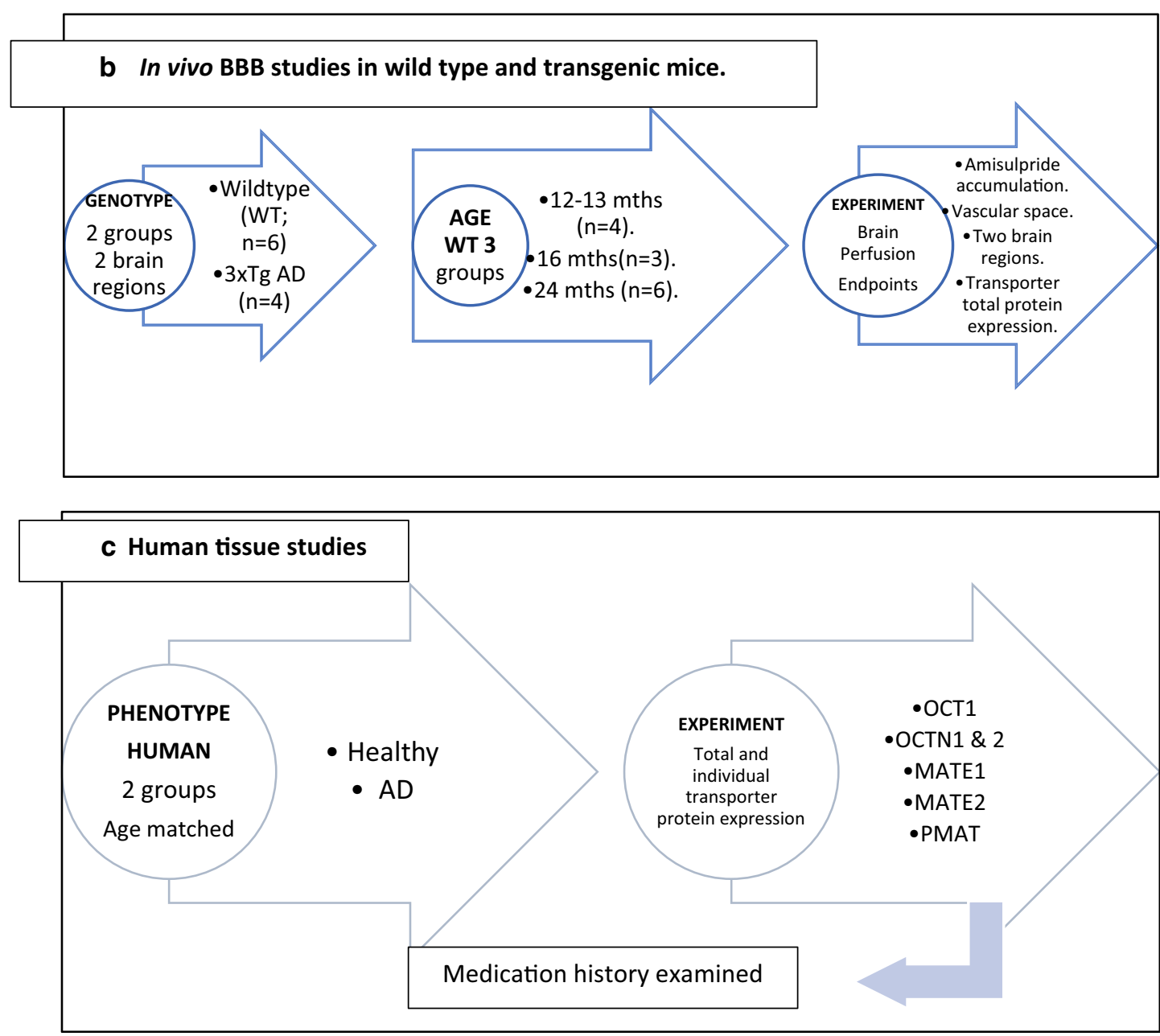

Fig. 1 Flow charts to provide an overview of the experimental design for the in silico, in vitro and in vivo approaches. Experiments from the three approaches were performed in parallel 
mmol; 99\% radiochemical purity: cat\# MC266) was purchased from Moravek Biochemicals, USA. Amisulpride (MW369.5, >98\% purity) was purchased from Cayman Chemicals, UK (cat\#71675-85-9). Haloperidol (MW375.9; $>98 \%$ purity) was purchased from Sigma-Aldrich, Dorset, UK (cat\#H1512). Anti-SLC22A1 antibody (Cat\#ab55916; RRID:AB_882579), Anti-SLC22A2 antibody (Cat\#ab170871: RRID:AB_2751021, Anti-SLC22A3 antibody (Cat\#ab183071; RRID:AB_2751016), Anti-SLC22A4 antibody (Cat\#ab200641; RRID:AB_2751017), Anti-SLC22A5 antibody (Cat\#ab180757; RRID:AB_2751018), Anti-SLC47A1 antibody (Cat\#ab104016: RRID:AB_10711136), AntiSLC47A2 (Cat\#ab174344: RRID:AB_2751019), SLC29A4 antibody (Cat\#ab56554: RRID:AB_2190909), Goat AntiRabbit IgG H\&L (cat\#ab6721: RRID:AB_955447) and Rabbit anti-mouse HRP (Cat\#ab6728: RRID:AB_955440) were purchased from Abcam, UK. Anti-SLC47A1 (Cat\#ab174344: RRID:AB_2751019) was purchased from Alomone Laboratories, Israel. Anti-SLC29A4 (Cat\#: bs-4176R: RRID:AB_11108960) was purchased from Bioss antibodies, USA. Goat anti-rabbit (IgG)-HRP was purchased from (Cell Signalling. Cat\#7074S:AB_2099233). Transferrin receptor monoclonal antibody was purchased from (Thermo Fisher
Scientific, CAT\# 13-6800 RRID: AB_2533029). Table 1 details the dilutions used. All consumables were purchased within the years 2012 to 2018 except the transferrin receptor antibody which was purchased in 2019.

\section{In vitro model of the BBB \\ Cell culture}

The hCMEC/D3 (human) and bEnd.3 (mouse) are wellestablished models of the BBB [21,30-32]. They are not listed on the misidentified cell line register (version 9 released 14th October 2018). Both lines require different mediums to grow to confluence and their BBB phenotype has been confirmed using Western blots, confocal and transmission electron microscopy [32] "Western Blot procedure" section). Functional expression of several transporters has been demonstrated by our group [32-34].

a. hCMEC/D3 cells (passages 27-35) were provided under a MTA and maintained in Clonetics ${ }^{\circledR}$ endothelial cell growth medium-2 MV Bullet Kit (Cat\# CC-3162 Lonza, UK) containing the endothelial basal medium, the SingleQuotsTM growth factor kit, foe-

Table 1 Primary and secondary antibodies used for protein expression studies

\begin{tabular}{|c|c|c|}
\hline Protein & Primary antibody & Secondary antibody Western blot (WB) \\
\hline OCT-1 (SLC22A1) & $\begin{array}{l}\text { Rabbit polyclonal anti-human and mouse (Abcam, Cat\#ab55916; } \\
\text { RRID:AB_882579), WB dilution-1:250 }\end{array}$ & $\begin{array}{l}\text { Goat anti-rabbit HRP (Abcam, cat\#ab6721: RRID:AB_955447) } \\
\text { dilution-1:1000 }\end{array}$ \\
\hline OCT-2 (SLC22A2) & $\begin{array}{l}\text { Rabbit monoclonal to human and mouse (Abcam, } \\
\text { Cat\#ab170871: RRID:AB_2751021), WB dilution—1:2000 }\end{array}$ & $\begin{array}{l}\text { Goat anti-rabbit HRP (Abcam, cat\#ab6721: RRID:AB_955447) } \\
\text { dilution-1:2000 }\end{array}$ \\
\hline OCT-3 (SLC22A3) & $\begin{array}{l}\text { Rabbit polyclonal to human and mouse (Abcam, Cat\#ab183071; } \\
\text { RRID:AB_2751016), WB dilution-1:600 }\end{array}$ & $\begin{array}{l}\text { Goat anti-rabbit HRP (Abcam, cat\#ab6721: RRID:AB_955447) } \\
\text { dilution-1:2000 }\end{array}$ \\
\hline OCTN1 (SLC22A4) & $\begin{array}{l}\text { Rabbit polyclonal to human and mouse (Abcam, Cat\#ab200641; } \\
\text { RRID:AB_2751017), WB dilution-1:1000 }\end{array}$ & $\begin{array}{l}\text { Goat anti-rabbit (lgG)-HRP (Cell Signalling. } \\
\text { Cat\#7074S:AB_2099233) dilution-1:1000 }\end{array}$ \\
\hline OCTN2 (SLC22A5) & $\begin{array}{l}\text { Rabbit polyclonal to human and mouse (Abcam, Cat\#ab180757; } \\
\text { RRID:AB_2751018), WB dilution-1:1000 }\end{array}$ & $\begin{array}{l}\text { Goat anti-rabbit (lgG)-HRP (Cell Signalling. Cat\#7074S: } \\
\text { AB_2099233) dilution—1:1000 }\end{array}$ \\
\hline MATE1 (SLC47A1) & $\begin{array}{l}\text { Rabbit polyclonal to human from Abcam (Cat\#ab104016: RRID } \\
\text { AB_10711136), WB dilution_-1:500 }\end{array}$ & $\begin{array}{l}\text { Goat anti-rabbit HRP (Abcam, Cat\#ab6721: RRID:AB_955447) } \\
\text { dilution-1:2000 }\end{array}$ \\
\hline MATE1 (SLC47A1) & $\begin{array}{l}\text { Rabbit polyclonal to mouse from Alomone labs (Cat\#ANT-131: } \\
\text { RRID:AB_2751020), WB dilution-1:800 }\end{array}$ & $\begin{array}{l}\text { Goat anti-rabbit HRP (Abcam, Cat\#ab6721: RRID:AB_955447) } \\
\text { dilution-1:2000 }\end{array}$ \\
\hline MATE2 (SLC47A2) & $\begin{array}{l}\text { Rabbit polyclonal to human and mouse (Abcam, Cat\#ab174344: } \\
\text { RRID:AB_2751019), WB dilution-1:500 }\end{array}$ & $\begin{array}{l}\text { Goat anti-rabbit HRP (Abcam, Cat\#ab6721:RRID:AB_955447) } \\
\text { dilution—1:2000 }\end{array}$ \\
\hline PMAT (SLC29A4) & $\begin{array}{l}\text { Mouse monoclonal to human and rat (Abcam, Cat\#ab56554: } \\
\text { RRID:AB_2190909), WB dilution-1:500 }\end{array}$ & $\begin{array}{l}\text { Rabbit anti-mouse HRP (Abcam, Cat\#ab6728: RRID:AB_955440) } \\
\text { dilution 1:2000 }\end{array}$ \\
\hline PMAT (SLC29A4) & $\begin{array}{l}\text { Rabbit polyclonal to human, mouse and rat (Bioss Antibodies; } \\
\text { Cat\#:bs-4176R: RRID:AB_11108960), WB Dilution_-1:800 for } \\
\text { hCMEC/D3_-1:650 for b.End3, 1:600 mouse capillaries }\end{array}$ & $\begin{array}{l}\text { Goat anti-rabbit (lgG)-HRP (Cell Signalling. Cat\#7074S: } \\
\text { RRID:AB_2099233) dilution—1:1000 }\end{array}$ \\
\hline TfR & $\begin{array}{l}\text { Transferrin receptor monoclonal antibody (Thermo Fisher Sci- } \\
\text { entific, CAT\# 13-6800: RRID: AB_2533029), WB Dilution—1:1000 }\end{array}$ & $\begin{array}{l}\text { Rabbit polyclonal Secondary to Mouse lgG_HRP (Abcam, CAT\# } \\
\text { ab6728 RRID: 955_440) WB dilution—1:1000 }\end{array}$ \\
\hline GAPDH & $\begin{array}{l}\text { Rabbit polyclonal to GAPDH (Abcam, Cat\#ab9485: } \\
\text { RRID:AB_307275), WB dilution 1: } 2500 \text { or 1:10,000 }\end{array}$ & \\
\hline
\end{tabular}

The predicted antibodies with their predicted molecular weight (MW) WB were all made up in PBS-T with 5\% BSA. Actual band sizes may differ due to post translational modifications or cleavages. (Validation data is available from the Abcam website (https://www.abcam.com/nav/primary-antibodies), cell signalling technology website (https://www.cellsignal.co.uk) and Alonome labs website (https://www.alomone.com). Accessed 19.10.18. Validation data is available from the BIOSS USA antibodies website (http://www.biossusaantibodies.com). Accessed 4.12.18. Verification data is available from ThermoFisherScientific (https://www.therm ofisher.com). Accessed 20.11.2019 
tal bovine serum (FBS), penicillin-streptomycin and HEPES (Sigma-Aldrich, UK) [32, 34, 35].

b. bEnd.3 cells (passages 17-25), isolated from the SV129 strain of mice and transformed with the Polyoma virus middle T-antigen, were purchased from $\mathrm{ATCC}^{\circledR}$ and underwent authentication tests during the accessioning process (CRL-2299: RRID:CVCL0170) [36]. They were grown in T-75 flasks (Fisher Scientific, cat\# 15350591) using high glucose Dulbeccos Modified Eagles Medium (SigmaAldrich, UK, cat\# D6429) supplemented with 10\% FBS (vol/vol) and 1\% penicillin-streptomycin (vol/ vol: Fisher Scientific cat\#10003927).

Both lines were maintained at $37{ }^{\circ} \mathrm{C} / 5 \% \mathrm{CO}_{2}$ in an incubator with saturated humidity. Medium was changed every 2-3 days. Cells were split when they reached 80-90\% confluency and were seeded onto 96-well plates (ThermoScientific, UK) at 20,000 cells $/ \mathrm{cm}^{2}$ for b.End3 cells and 25,000 cells $/ \mathrm{cm}^{2}$ for hCMEC/D3 cells. The hCMEC/D3 96-well plates were pre-coated with $0.1 \mathrm{mg} /$ $\mathrm{ml}$ rat tail collagen type1 (Gibco cat\#A1048301).

Both lines were confluent in 4-5 days and were left for another 4 days to allow for further differentiation before experimentation. The medium was changed every 2-3 days.

\section{Drug accumulation assay}

Accumulation assays were performed on confluent cell monolayers grown in the centre 60 wells of 96 -well plates. Each passage was regarded as one ' $n$ '. No sample calculation was performed. The accumulation buffer ( $\mathrm{pH7.4)}$ composition was $135 \mathrm{mM} \mathrm{NaCl}, 10 \mathrm{mM}$ HEPES, $5.4 \mathrm{mM}$ $\mathrm{KCl}, 1.5 \mathrm{mM} \mathrm{CaCl}_{2}, 1.2 \mathrm{mM} \mathrm{MgCl}_{2}$, and $1.1 \mathrm{mM}$ D-glucose and water. It also contained 3.7-7.7 nM [Omethyl$\left.{ }^{3} \mathrm{H}\right]$ amisulpride and $9.4 \mu \mathrm{M}\left[{ }^{14} \mathrm{C}(\mathrm{U})\right]$ sucrose or $10 \mathrm{nM}$ $\left[{ }^{3} \mathrm{H}\right]$ haloperidol and $3.8 \mu \mathrm{M}\left[{ }^{14} \mathrm{C}\right]$ sucrose. $\left[{ }^{14} \mathrm{C}\right]$ sucrose is a similar size to the test molecules and was used as an inert marker of extracellular space and membrane integrity. After the exposure period, buffer was aspirated and the wells washed with ice-cold $\mathrm{PBS}^{+}$(Sigma-Aldrich, UK) to remove drug that was not taken up by cells and to stop further transport. 1\% Triton X-100 (Sigma-Aldrich) was added and the plate was incubated for an hour at $37{ }^{\circ} \mathrm{C}$ to lyse the cells and to release accumulated $\left[{ }^{3} \mathrm{H}\right]$ drug. $100 \mu \mathrm{l}$ from each of the wells was transferred to a vial and scintillation fluid $(4 \mathrm{ml})$ added (Optiphase Hisafe 2, PerkinElmer, UK). Radioactivity was measured using a Packard Tri-Carb 2900TR liquid scintillation counter (PerkinElmer, UK) and corrected for background. The remaining $100 \mu \mathrm{l}$ in each well were used to perform a bicinchoninic acid (BCA) protein assay. A range of 2-30 $\mu \mathrm{mg}^{-1}$ of protein was acceptable. All data for $\left[{ }^{3} \mathrm{H}\right]$ amisulpride or $\left[{ }^{3} \mathrm{H}\right]$ haloperidol were expressed as a volume of distribution $\left(\mathrm{V}_{\mathrm{d}}\right)$ after correction for $\left[{ }^{14} \mathrm{C}\right]$ sucrose. The $V_{d}$ was calculated from the sum of accumulated radioactivity (a sum of efflux and influx of the molecule) (disintegrations per minute $(\mathrm{dpm}) / \mathrm{mg}$ protein) over the ratio of $\mathrm{dpm} / \mu \mathrm{l}$ of accumulation buffer. Outliers were identified by examining the $\left[{ }^{14} \mathrm{C}\right]$ sucrose values. $\left[{ }^{14} \mathrm{C}\right]$ sucrose values are presented in the figures and tables.

\section{Transporter inhibition assay}

Transporter interaction was examined by incubating $\left[{ }^{3} \mathrm{H}\right]$ amisulpride and $\left[{ }^{14} \mathrm{C}\right]$ sucrose with potential inhibitors. These included unlabelled amisulpride and inhibitors/ substrates of OCT, OCTN, MATE, PMAT, P-gp, BCRP, and MRP at established concentrations (Additional file 1: Table S1). The MATE1 inhibitor, famotidine, was also utilized at a higher concentration of $2 \mu \mathrm{M}$. ATP depletion (Promega Enliten assay) was carried out by pre-incubation with the glycolysis inhibitor, $10 \mathrm{mM}$ 2-deoxy-D-glucose, for an hour before incubating the cells with $\left[{ }^{3} \mathrm{H}\right]$ amisulpride and $\left[{ }^{14} \mathrm{C}\right]$ sucrose. This assay had previously been shown to inhibit drug efflux by our group [32, 34].

\section{Cytotoxicity assay}

Cytotoxicity of amisulpride $(0.1-20 \mu \mathrm{M})$ and eflornithine $(250-500 \mu \mathrm{M})$ on both cell lines was assessed using 3-(4,5-dimethylthiazol-2-yl)-2,5-diphenyltetrazolium bromide (MTT) assay [32]. The results were expressed as a percentage of cell viability. This assay was also utilized on hCMEC/D3 cells (passage 32 and/or 33) for $2 \mathrm{~h}$ to assess toxicity of $1 \mu \mathrm{M}$ famotidine, $2 \mu \mathrm{M}$ famotidine, $2 \mu \mathrm{M}$ lopinavir, $20 \mu \mathrm{M}$ ergothioneine, $5 \mu \mathrm{M}$ L-carnitine, $3 \mu \mathrm{M}$ nifekalant hydrochloride and $1.5 \mu \mathrm{M}\left[{ }^{14} \mathrm{C}\right]$ sucrose. We have already published MTT assay results for eflornithine $(250 \mu \mathrm{M})$ in hCMEC/D3 cells and haloperidol $(40 \mu \mathrm{M})$, dexamethasone $(200 \mu \mathrm{M})$, pentamidine $(10 \mu \mathrm{M})$, ko143 $(1 \mu \mathrm{M})$, MK571 $(10 \mu \mathrm{M})$, amantadine $(500 \mu \mathrm{M})$, corticosterone $(50 \mu \mathrm{M})$, pheophorbide $\mathrm{A}(1 \mu \mathrm{M})$ and prazosin $(100 \mu \mathrm{M})$ in both cell lines [32, 34]. No significant effect was observed except with prazosin on bEnd. 3 cells.

\section{Lipophilicity}

Lipophilicity is a standard physicochemical measure which is very important in terms of understanding drug distribution across membranes including the $\mathrm{BBB}$ and can be expressed in the form of an octanol-saline partition coefficient. The higher the lipophilicity the greater the ability of the molecule to cross the plasma membrane by passive diffusion. An octanol-saline partition coefficient for $\left[{ }^{3} \mathrm{H}\right]$ amisulpride and $\left[{ }^{3} \mathrm{H}\right]$ haloperidol was determined [37]. 


\section{In silico computational study}

Using in silico molecular docking, we tested the molecular level interactions of amisulpride, haloperidol and prazosin (OCT1 and OCT3 substrate) with the transporters OCT1, PMAT and MATE1. Due to the unavailability of the crystal structures of these transporters, molecular models of OCT1, PMAT and MATE1 were developed using homology modelling with Swiss-model webserver using PDB codes 4PYP, 5 Y50 and 4ZOW, respectively, as templates (Additional file 1). A further molecular docking study was performed to explore the interaction of amisulpride, dexamethasone (P-gp substrate) and colchicine (P-gp substrate) in the binding site of the multidrug transporter ABCB1 (P-glycoprotein), and the pbd code 6FN1 [38] was used as the template. Molecular docking was performed using Dock Ligands (CDOCKER) protocol from Discovery studio version 4.0. CDOCKER is an implementation of a CHARMm based docking tool where each orientation is subjected to simulated annealing molecular dynamics. The binding sites were chosen after comparing the docking results of the ligands in all possible binding cavities within the transporters.

\section{Animal model of AD}

All experiments were performed in accordance with the Animal Scientific Procedures Act (1986) and Amendment Regulations 2012 and with consideration to the ARRIVE guidelines. The study was approved by the King's College London Animal Welfare and Ethical Review Body and performed under license: 70/7755. A total of 40 mice were used for this study. Mice were housed at King's College London. C57BL6/129 mice (wild-type) and the triple transgenic $\mathrm{AD}$ model $(3 \times \mathrm{TgAD})$ of $\mathrm{C} 57$ mice which harbour the human APP-Swedish mutation (KM670/671NL), tau mutation (P301L), and presenilin-1 mutation (M146V) were utilized at 12-13 (mid-age), 16 (old) or 24 (elderly) months old. The $3 \times \mathrm{TgAD}$ is an established AD model displaying the temporal and spatial progression and mirroring the neuropathological development seen in AD [39]. These mice were bred and genotyped at King's College London and were a gift. They had originally been supplied by the Jackson Laboratory (RRID:IMSR_JAX:008880). No sample size calculation was performed and the study was not pre-registered. Previous experience suggested that even with the limited number of animals available there would still be sufficient power (95\%) to detect significant differences $(p<0.05)[40]$. Welfare was assessed daily by animal technologists. Animals were identified by earmarks and housed together by age and genotype in guideline compliant cages. All animals were maintained under standard temperature/lighting conditions and given food and water ad libitum. The experiment on each animal had to be performed within set time frames to allow the three age groups to be achieved. Experiments were performed between $9 \mathrm{am}$ and $5 \mathrm{pm}$. The experimenter was not blinded.

The median life span of $3 \times \mathrm{TgAD}$ mice has been reported to be 673 days ( 22 months) which is shorter than the 907 day (30 months) lifespan of C57BL/6J [41]. Adult male BALB/c mice (inbred strain) were purchased from Harlan UK Limited (Oxon, UK). All mice were anaesthetised $(2 \mathrm{mg} / \mathrm{kg}$ i.p. medetomidine hydrochloride and $150 \mathrm{mg} / \mathrm{kg}$ i.p. ketamine) and heparinized (100 U i.p.) in a procedure room separate to the laboratory where the brain perfusion was performed. Advice was sought from the named veterinary surgeon regarding the anaesthetic.

\section{In situ brain perfusion}

To assess differences in $\left[{ }^{3} \mathrm{H}\right]$ amisulpride and $\left[{ }^{14} \mathrm{C}\right]$ sucrose transport into the brain in ageing and in $\mathrm{AD}$, wildtype $($ C57BL6/129 $\mathrm{n}=17)$ and transgenic AD $(3 \times \mathrm{Tg} \mathrm{n}=6)$ mice were used. Perfusion (10 $\mathrm{min} ; 5 \mathrm{ml} / \mathrm{min}$ ) with a warmed $\left(37{ }^{\circ} \mathrm{C}\right)$ and oxygenated $\left(95 \% \mathrm{O}_{2} ; 5 \% \mathrm{CO}_{2}\right)$ artificial plasma was via a cannula in the left ventricle of the heart as previously described [42]. The artificial plasma consisted of a modified Krebs-Henseleit mammalian Ringer solution with the following constituents: $117 \mathrm{mM}$ $\mathrm{NaCl}$, $4.7 \mathrm{mM} \mathrm{KCl}, 2.5 \mathrm{mM} \mathrm{CaCl} 2,1.2 \mathrm{mM} \mathrm{MgSO}_{4}$, $24.8 \mathrm{mM} \mathrm{NaHCO}, 1.2 \mathrm{mM} \mathrm{KH}_{2} \mathrm{PO}_{4}, 10 \mathrm{mM}$ glucose, and $1 \mathrm{~g} / \mathrm{l}$ bovine serum albumin. With the start of perfusion the right atrium of the heart was sectioned to prevent the recirculation of the artificial plasma. At the end of perfusion the animal was decapitated and the brain removed. To determine the brain concentration of $\left[{ }^{3} \mathrm{H}\right]$ amisulpride, frontal and occipital cortex samples were taken and weighed using a Leica S4E microscope (Purchased 2005). Brain samples were then solubilized with $0.5 \mathrm{ml}$ of Solvable (PerkinElmer, USA) and liquid scintillation fluid (3.5 ml; Lumasafe; PerkinElmer) added. Radioactivity in the samples were determined using the Tri-Carb2900TR scintillation counter (Purchased 2007).

\section{Expression of results}

Radioactive concentrations in the brain samples $(\mathrm{dpm} / \mathrm{g})$ were expressed as a percentage of that in the artificial plasma $(\mathrm{dpm} / \mathrm{ml})$ and termed $\mathrm{R}_{\text {TISSUE }}$ (millilitres $/ 100 \mathrm{~g}$ ). All $R_{\text {TISSUE }}$ values for $\left[{ }^{3} \mathrm{H}\right]$ amisulpride were corrected for vascular/extracellular space by subtracting the $\left[{ }^{14} \mathrm{C}\right]$ sucrose $R_{\text {TISSUE }}$ value. Examination of the $\left[{ }^{14} \mathrm{C}\right]$ sucrose values (i.e. vascular space) and comparison to previously published values determines if the result is an outlier. This is acceptable for the WT animals, however, it is noted that $\left[{ }^{14} \mathrm{C}\right]$ sucrose (vascular space) may be affected in AD. No outliers were detected in this study. 


\section{hCMEC/D3 and b.End3 monolayers isolation}

In order to perform Western blots, cell lines were grown to confluence in T-75 flasks (Thermo Scientific, UK) and left for 3-4 days, as previously described. The flask was then transferred to ice and the medium removed, before the cells were washed twice using ice-cold PBS+. Then, $1 \mathrm{ml}$ of ice-cold Radio-Immunoprecipitation Assay (RIPA) buffer (Sigma-Aldrich, Dorset, UK) with added protease inhibitors $(10 \% \mathrm{v} / \mathrm{v})$ (Thermo Scientific, Loughborough, UK) was added to the flask to lyse the cells. A plastic cell scraper (Greiner Bio-One Ltd, Gloucestershire, UK) was used to scrape the cells off the bottom of the flask and the cell lysate was transferred to a precooled $1.5 \mathrm{ml}$ Eppendorf tube which was left on ice for $20 \mathrm{~min}$. The tubes were then centrifuged at 10,000 rpm for $10 \mathrm{~min}$ at $4{ }^{\circ} \mathrm{C}$ using a Thermo Electron Corporation Heraeus Frescol7 bench-top micro-centrifuge. After centrifugation, the supernatant was transferred to another pre-cooled $1.5 \mathrm{ml}$ Eppendorf and the pellet discarded. The resulting supernatant was taken for Western blot analysis.

\section{Mouse brain capillary isolation}

Brain capillaries from old-age (16 months) wild-type (3 females) and $3 \times \operatorname{TgAD}$ ( 3 males, 1 female) mice were used to explore MATE1 expression. Brain capillaries were also isolated from elderly (24 month) age-matched wild-type C57BL6/129 mice (3 males, 2 females) and $3 \times$ TgAD mice ( 3 males, 2 females) for all other transporter studies. The left ventricle of the heart was cannulated and perfused $(5 \mathrm{ml} / \mathrm{min})$ with an oxygenated artificial plasma (modified Krebs-Henseleit mammalian Ringer) for up to $2 \mathrm{~min}$. The right atrium was sectioned before perfusion was started. The mice were then decapitated and the perfused brain removed. The brain was homogenized in physiological buffer (brain weight $\times 3$ ) and $26 \%$ dextran (brain weight $\times 4$ ). The homogenate was subjected to density gradient centrifugation $(5400 \times g$ for $15 \mathrm{~min}$ at $4{ }^{\circ} \mathrm{C}$ ) to give an endothelial cell-enriched pellet and the supernatant was discarded [42]. $300 \mu \mathrm{l}$ of ice-cold RIPA: ThermoFisher Scientific cat\#89900) buffer with added protease inhibitors was added to the pellet at $4{ }^{\circ} \mathrm{C}$ to lyse the tissue and then centrifuged at $8000 \times g$ for $15 \mathrm{~min}$ at $4{ }^{\circ} \mathrm{C}$. The resulting supernatant was taken for Western blot analysis.

\section{Human tissue}

Human tissue was provided with informed consent via the brains for dementia research (BDR) and were anonymized. BDR has ethical approval granted by the national health service (NHS) health research authority (NRES Committee London-City \& East, UK: REC reference: 08/H0704/128+5. IRAS project ID:120436).
Tissue was received on the basis that it will be handled, stored, used and disposed of within the terms of the Human Tissue Act 2004. Post-mortem brain capillaries from healthy individuals (Braak stage 0-II; $86.8 \pm 1.5$ years; 2 females, 3 males) and AD cases (Brak stage V-VI; $79.4 \pm 3.7$ years; 2 females, 3 males) were used to investigate the expression of transporters (Case details-Additional file 1: Table S2). Medication history of the cases was supplied by the Manchester Brain Bank (Additional file 1: Table S3). In this study we identified those drugs prescribed as sedatives, antidepressants and antipsychotics.

\section{Human brain microvasculature isolation}

Brain capillaries from frontal cortex, caudate nucleus, and putamen samples were isolated after homogenising $300 \mathrm{mg}$ tissue and carrying out a dextran-based densitygradient centrifugation to produce a capillary-enriched pellet.

The pellet was further lysed with $500 \mu \mathrm{l}$ of ice-cold RIPA buffer with added protease inhibitors at $4{ }^{\circ} \mathrm{C}$ and then centrifuged at $8000 \times g$ for $15 \mathrm{~min}$ at $4{ }^{\circ} \mathrm{C}$. The resulting supernatant was taken for Western blot analysis to examine transporter expression. The presence of transferrin receptor in the supernatant indicated that the method generated samples containing capillary endothelial cells.

\section{Western Blot procedure}

The supernatant protein concentration was determined using a BCA assay (Albumin standard, ThermoScientific). The supernatants were diluted and boiled for $5 \mathrm{~min}$ at $95{ }^{\circ} \mathrm{C}$ in $5 \times$ Laemmli sample buffer. Cell lines $(30 \mu \mathrm{g}$ except for MATE 1 antibody in Bend. 3 cells where $15 \mu \mathrm{g}$ was utilized and PMAT antibody in hCMEC/D3 and bEnd. 3 cells where $20 \mu \mathrm{g}$ and $10 \mu \mathrm{g}$ was utilized respectively), mouse samples (15 $\mu \mathrm{g}$ for MATE1, OCTN1 and 2) and (30 $\mu \mathrm{g}$ for MATE2, PMAT and OCT1), human samples (10 $\mu \mathrm{g}$ for OCNT1 and 2) or 15-20 $\mu \mathrm{g}$ (for MATE1, MATE2, PMAT and OCT1) were loaded equally on 4-20\% Mini-PROTEAN ${ }^{\circledR}$ TGX $^{\mathrm{TM}}$ gels (Bio-Rad) alongside a molecular weight marker (Precision plus protein, Bio-Rad). Samples underwent SDS-PAGE at $160 \mathrm{~V}$ for $1 \mathrm{~h}$. Proteins were transferred onto $0.45 \mu \mathrm{m}$ polyvinylidene fluoride membranes (GE Healthcare, UK) after methanol activation at $100 \mathrm{~V}$ for $1 \mathrm{~h}$. Membranes were blocked to reduce nonspecific binding using 5\% milk with PBS-TWEEN ${ }^{\circledR}$ tablets (PBS-T) (Calbiochem, USA) at room temperature (RT) for $1 \mathrm{~h}$. Membranes were incubated overnight at $4{ }^{\circ} \mathrm{C}$ with primary antibodies in PBS-T (Table 1). Membranes were washed in PBS-T $(3 \times 10 \mathrm{~min})$ and incubated with the secondary antibody in PBS-T at RT for $1 \mathrm{~h}$. Further washing in PBS-T $(3 \times 10$ 
min), membranes were then incubated with enhanced chemiluminescent reagent (ThermoScientific) for $30 \mathrm{~s}$ at RT.

Quantification of protein expression was determined by calculating the intensity ratio of the band of interest and the band of the loading control (tubulin or GAPDH). Band intensity ratio analysis was conducted using ImageJ software (NIH). Our group have previously published results from Pgp, BCRP, OCT1, OCT2 and OCT3 protein expression studies of bEnd. 3 and hCMEC/D3 cells $[32,34]$.

\section{Data analysis}

Data are expressed as mean \pm SEM. The data was analysed by two-way ANOVA with Holm-Sidak post hoc test for the accumulation studies and in situ perfusion studies, one-way ANOVA with Tukey's post hoc test for MTT assay and Student's t-test or two-way ANOVA for Western blot data using Sigmaplot version 13 (Systat, USA) or GraphPad Prism 7.03. $\mathrm{p}<0.05$ were considered as statistically significant. Exact p-values are provided in figure legends/“Results" section.

\section{Results}

\section{Amisulpride accumulation and saturable transport}

$\left[{ }^{3} \mathrm{H}\right]$ Amisulpride was able to accumulate in both hCMEC/D3 and bEnd3 cell lines to a greater extent than the baseline marker, $\left[{ }^{14} \mathrm{C}\right]$ sucrose (Fig. 2 and Additional file 1: Figure S1). Incubation of hCMEC/D3 and bEnd3 cell lines with $20 \mu \mathrm{M}$ amisulpride significantly decreased the accumulation of $\left[{ }^{3} \mathrm{H}\right]$ amisulpride $(6.5 \mathrm{nM})$ at $5 \mathrm{~min}-$ with a significant decrease of $37 \%$ in hCMEC/D3 cells and a decrease of $50 \%$ in bEnd. 3 cells observed after $2 \mathrm{~h}$ (Fig. 2). No significant differences were observed for $\left[{ }^{14} \mathrm{C}\right]$ sucrose between the treatments, except in the bEnd3 cells at $120 \mathrm{~min}$ where the presence of $20 \mu \mathrm{M}$ amisulpride decreased the accumulation of $\left[{ }^{14} \mathrm{C}\right]$ sucrose (Additional file 1: Figure $\mathrm{S} 1$ ). However, all $\left[{ }^{14} \mathrm{C}\right]$ sucrose values were within the expected range for these in vitro models. Studies also revealed that lower concentrations of unlabelled amisulpride $(0.1 \mu \mathrm{M})$ did not affect accumulation of $\left[{ }^{3} \mathrm{H}\right]$ amisulpride in hCMEC/D3 ( $\mathrm{n}=5$ passages) or bEnd.3 $(\mathrm{n}=3$ passages) cells at all time points (data not shown).

\section{$A B C$ transporter involvement}

ATP depletion did not affect the accumulation of $\left[{ }^{3} \mathrm{H}\right]$ amisulpride or $\left[{ }^{14} \mathrm{C}\right]$ sucrose in either cell line (Additional file 1: Figure S2). The P-gp substrate, dexamethasone, BCRP substrate, ko143, and inhibitor, pheophorbide A, and MRP family inhibitor, MK571, did not affect the accumulation of $\left[{ }^{3} \mathrm{H}\right]$ amisulpride or $\left[{ }^{14} \mathrm{C}\right]$ sucrose in either cell line (Additional file 1: Figure S3).

\section{OCT, OCTN, PMAT and MATE involvement}

Involvement of OCTs in $\left[{ }^{3} \mathrm{H}\right]$ amisulpride uptake was investigated by incubating hCMEC/D3 and bEnd. 3 cells with the, OCT 1 and 2 substrate, amantadine, the OCT 1 and 3 substrate, prazosin, and the OCT3 substrate, corticosterone (Additional file 1: Figure $\mathrm{S} 4$ ). $\left[{ }^{3} \mathrm{H}\right] \mathrm{ami}-$ sulpride accumulation did not change in the presence of amantadine in hCMEC/D3 cells, but significantly increased by $84 \%$ in bEnd. 3 cells. In the presence of prazosin, there was a significantly reduced accumulation of $\left[{ }^{3} \mathrm{H}\right]$ amisulpride in hCMEC/D3 cells, but not in bEnd.3
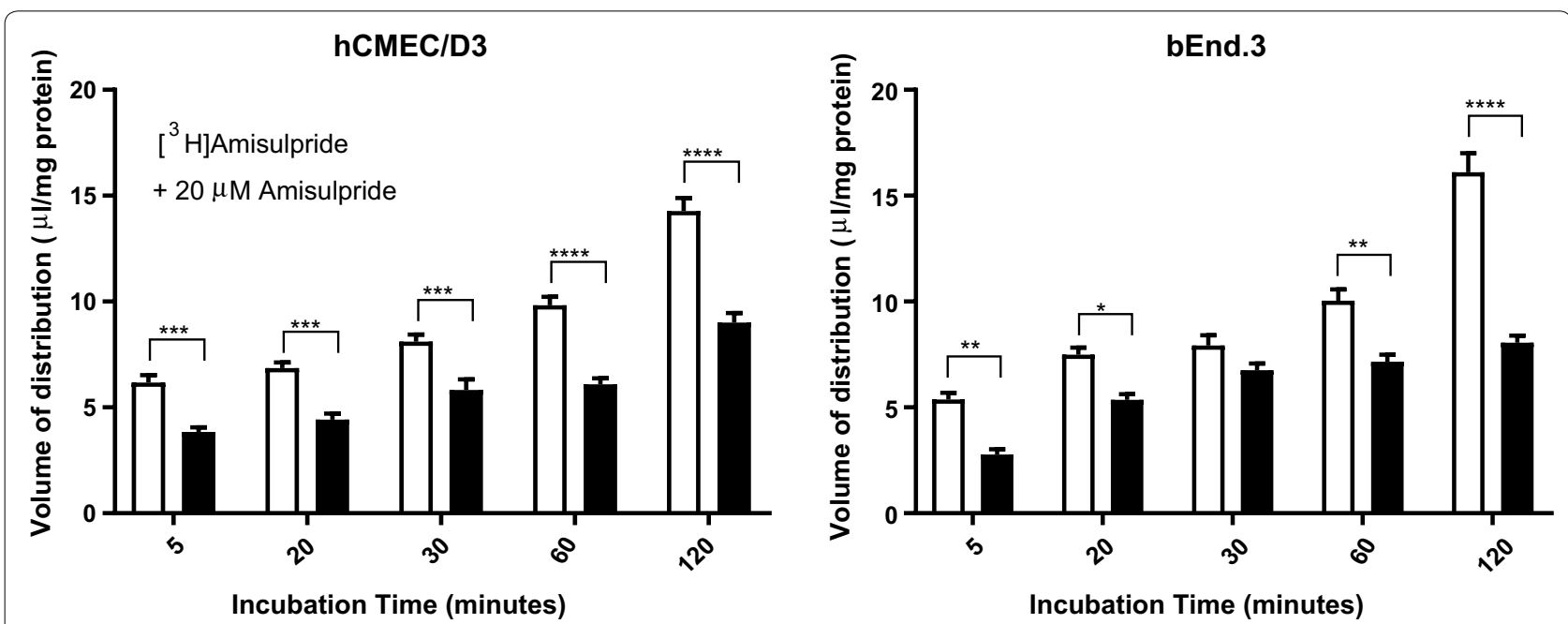

Fig. 2 The effect of self-inhibition $(20 \mu \mathrm{M})$ on the accumulation of $\left[{ }^{3} \mathrm{H}\right]$ amisulpride $(6.5 \mathrm{nM})$ was determined in hCMEC/D3 (a) and bEnd.3 (b) cell lines. Significant differences compared to control were observed- ${ }^{*} p \leq 0.05,{ }^{* *} p \leq 0.01,{ }^{* * *} p \leq 0.001,{ }^{* * * *} p \leq 0.0001$. All data have been corrected for $\left[{ }^{14} \mathrm{C}\right]$ sucrose and are expressed as mean \pm S.E.M, $n=3$ to 7 plates with 6 replicates (wells) per timepoint per plate (5 time-points) 
cells. Corticosterone did not affect the accumulation of $\left[{ }^{3} \mathrm{H}\right]$ amisulpride in either cell line. No differences were found for $\left[{ }^{14} \mathrm{C}\right]$ sucrose between the treatments (Additional file 1: Figure S4).

$\left[{ }^{3} \mathrm{H}\right]$ amisulpride accumulation in hCMEC/D3 and b.End3 was unaffected by the presence of ergothioneine (OCTN1) and L-carnitine (OCTN2) respectively (Additional file 1: Figures S5 and S6). $\left[{ }^{14} \mathrm{C}\right]$ Sucrose $\mathrm{V}_{\mathrm{d}}$ was not significantly different between the treatments, except significant differences were observed between $\left[{ }^{14} \mathrm{C}\right]$ sucrose and $\mathrm{L}$-carnitine at $2 \mathrm{~h}$ suggestive that this time point for $\left[{ }^{3} \mathrm{H}\right]$ amisulpride should be ignored.

Incubation with the PMAT inhibitor, lopinavir, resulted in a significant increase in the $\mathrm{V}_{\mathrm{d}}$ of $\left[{ }^{3} \mathrm{H}\right] \mathrm{ami}-$ sulpride by $63.9 \%$ at $20 \mathrm{~min}, 83.2 \%$ at $30 \mathrm{~min}, 85.1 \%$ at $60 \mathrm{~min}$ and by $68.6 \%$ at $120 \mathrm{~min}$ (Fig. 3). The $\mathrm{V}_{\mathrm{d}}$ of $\left[{ }^{14} \mathrm{C}\right]$ sucrose was not significantly different between control and test groups (Fig. 3). No affect was observed with this inhibitor in the b.End3 cells (Additional file 1: Figure S7).

Incubation with the MATE1 inhibitor, famotidine $(1 \mu \mathrm{M})$ resulted in no significant effect on the $\mathrm{V}_{\mathrm{d}}$ of $\left[{ }^{3} \mathrm{H}\right]$ amisulpride in hCMEC/D3 cells (Fig. 4). The $\mathrm{V}_{\mathrm{d}}$ of $\left[{ }^{14} \mathrm{C}\right]$ sucrose was not significantly different between control and test groups with $(1 \mu \mathrm{M})$ famotidine during the standard $2 \mathrm{~h}$ incubation period. An assessment of the effect of $2 \mu \mathrm{M}$ famotidine on $\left[{ }^{14} \mathrm{C}\right]$ sucrose alone revealed a loss of $\mathrm{hCMEC} / \mathrm{D} 3$ integrity at $2 \mathrm{~h}$. Further assessment of famotidine $(2 \mu \mathrm{M})$ did not affect either $\left[{ }^{3} \mathrm{H}\right]$ amisulpride or $\left[{ }^{14} \mathrm{C}\right]$ sucrose accumulation in hCMEC/D3 cells over a $1 \mathrm{~h}$ period (Fig. 4). No affect was observed with famotidine
$(1 \mu \mathrm{M})$ in b.End3 with either $\left[{ }^{3} \mathrm{H}\right]$ amisulpride or $\left[{ }^{14} \mathrm{C}\right]$ sucrose (Additional file 1: Figure S7).

Incubation with the MATE2 inhibitor, nifekalant, resulted in no significant affect on the $\mathrm{V}_{\mathrm{d}}$ of $\left[{ }^{3} \mathrm{H}\right] \mathrm{ami}$ sulpride in hCMEC/D3 cells (Additional file 1: Figure S8). The $V_{d}$ of $\left[{ }^{14} C\right]$ sucrose was not significantly different between control and test groups up to 120 min with nifekalant suggesting loss of membrane integrity at this time point. No affect was observed with this inhibitor in b.End3 with either $\left[{ }^{3} \mathrm{H}\right]$ amisulpride or $\left[{ }^{14} \mathrm{C}\right]$ sucrose (Additional file 1: Figure S7).

\section{Interaction with the positively charged anti-psychotic drug, haloperidol}

The effect of the cationic drug, haloperidol $(40 \mu \mathrm{M})$, on radiolabelled amisulpride accumulation was also investigated. Incubation of unlabelled haloperidol with $\left[{ }^{3} \mathrm{H}\right]$ amisulpride did not yield any significant effects in either cell line (Additional file 1: Figure S9). No significant differences were found for $\left[{ }^{14} \mathrm{C}\right]$ sucrose between the treatments (Additional file 1: Figure S9).

\section{Characteristics of haloperidol accumulation in hCMEC/D3 and $b . E n d 3$ cell lines}

hCMEC/D3 and b.End3 cells were incubated with unlabelled haloperidol $(40 \mu \mathrm{M})$ along with $\left[{ }^{3} \mathrm{H}\right]$ haloperidol $(10 \mathrm{nM})$. Incubation with unlabeled haloperidol significantly decreased the accumulation of radiolabelled haloperidol by approximately $93 \%$ in hCMEC/D3 cell line and by $94 \%$ in bEnd. 3 cell line at all times ${ }^{* * * * *} \mathrm{p}<0.001$ ) (Additional file 1: Figure S10). No significant differences were
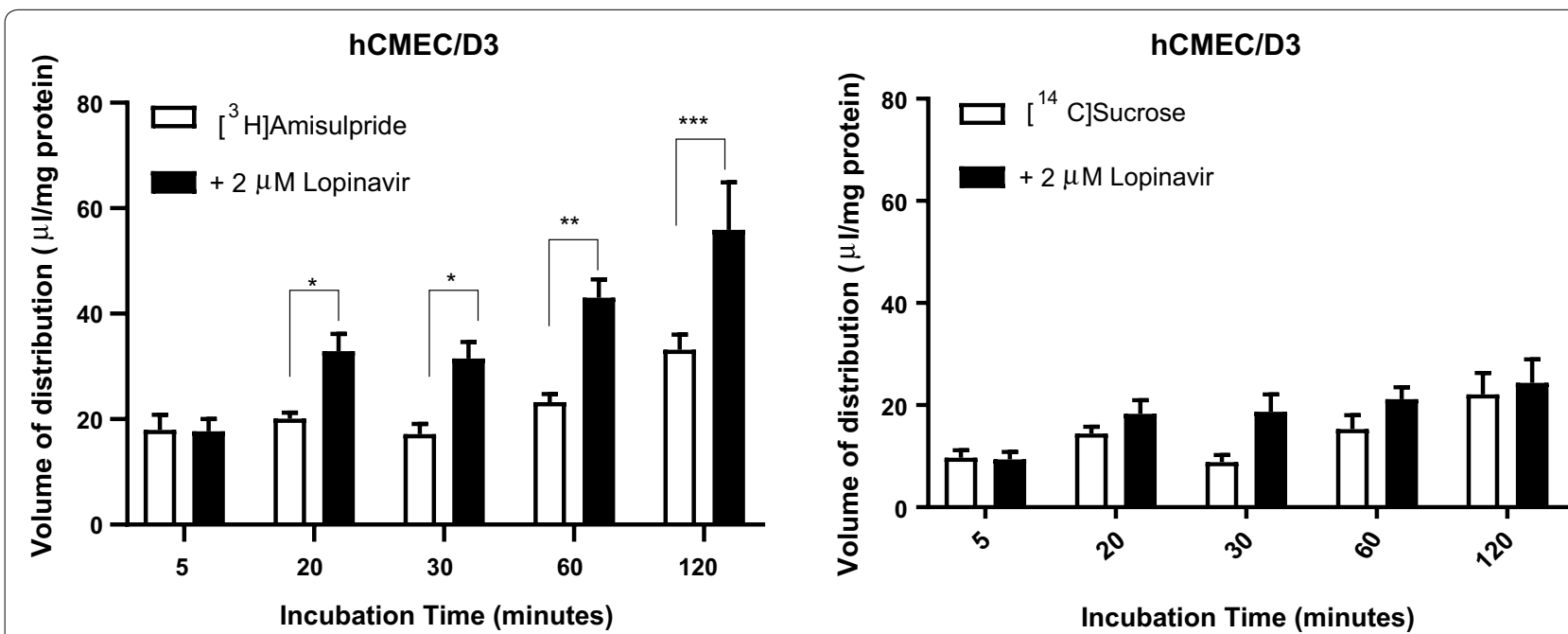

Fig. 3 The effect of PMAT inhibition on the accumulation of $\left[{ }^{3} \mathrm{H}\right]$ amisulpride (3.7-7.7 nM) was determined in hCMEC/D3 cell lines. Significant increases were observed compared to control ${ }^{* * *} p \leq 0.0001,{ }^{* * *} p \leq 0.001,{ }^{* *} p=0.01$ and ${ }^{*} p=0.05 .\left[{ }^{3} \mathrm{H}\right]$ amisulpride data has been corrected for $\left[{ }^{14} \mathrm{C}\right]$ sucrose and are expressed as mean \pm S.E.M, $n=5$ passages (p30, $2 \times p 31, \mathrm{p} 32$ and p34 for PMAT) with 6 replicates (wells) per timepoint per plate (5 time-points) 


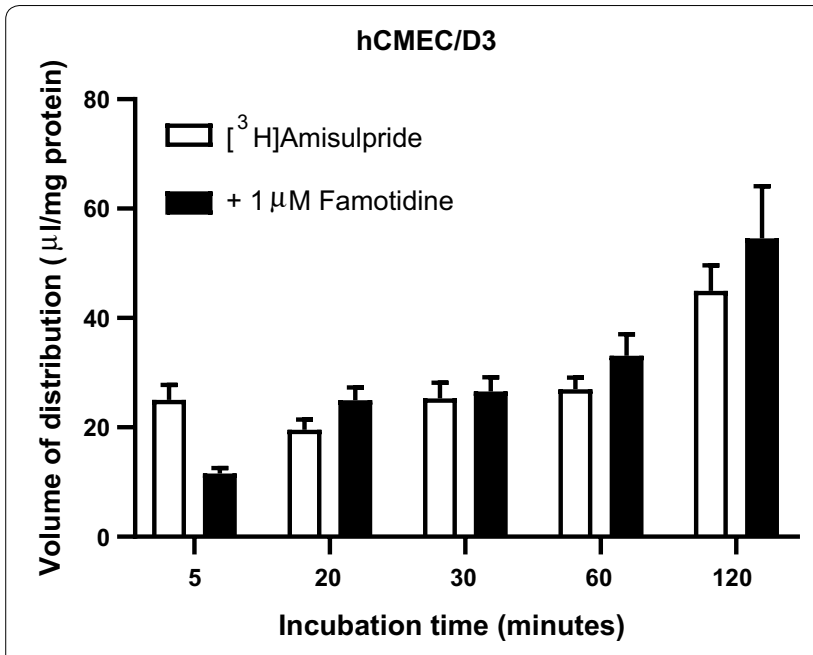

hCMEC/D3

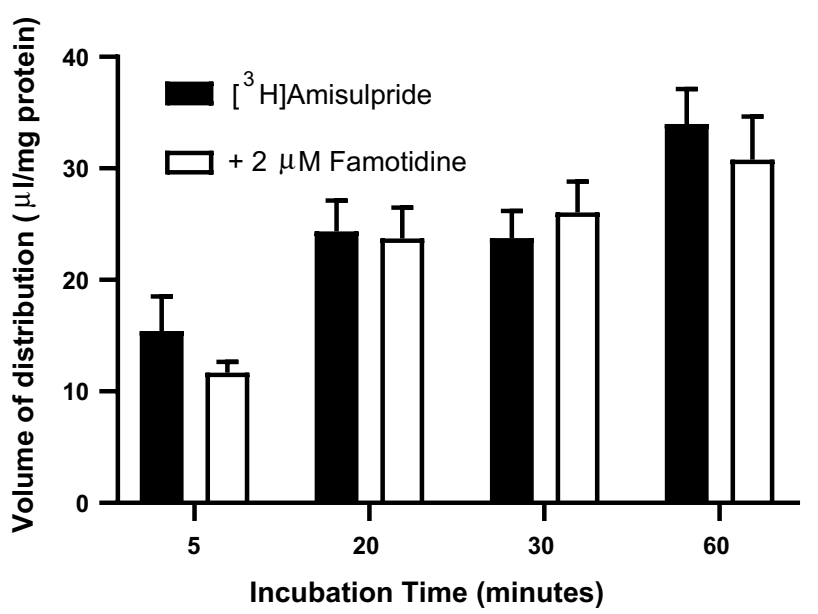

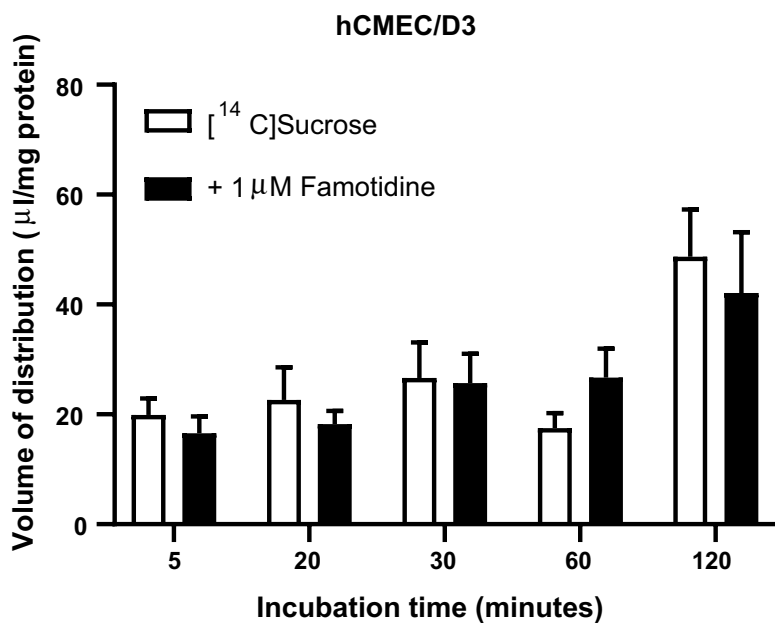

hCMEC/D3

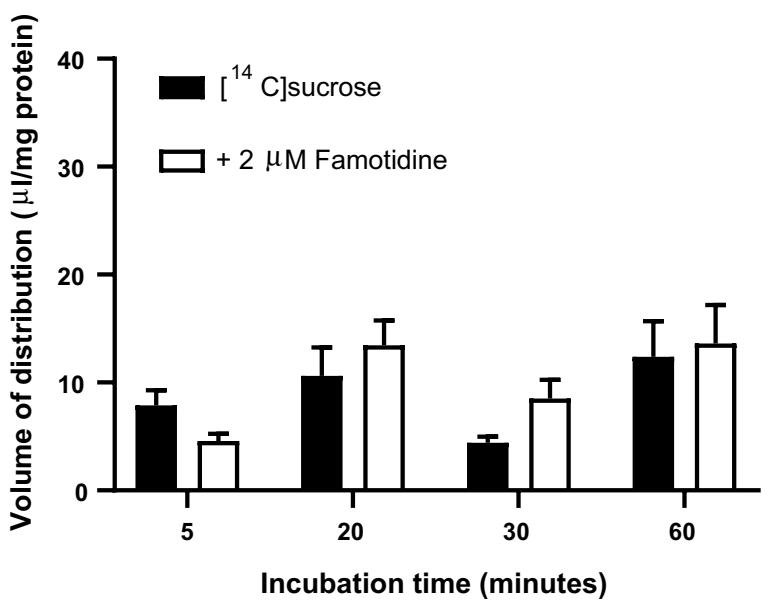

Fig. 4 The effect of MATE1 inhibition on the accumulation of $\left[{ }^{3} \mathrm{H}\right]$ amisulpride (3.7-7.7 nM) was determined in hCMEC/D3 cell lines. Significant increases were observed compared to control *** $p \leq 0.0001,{ }^{* * *} p \leq 0.001,{ }^{* *} p=0.01$ and ${ }^{*} p=0.05$. [ ${ }^{3} \mathrm{H}$ ]amisulpride data has been corrected for $\left[{ }^{14} \mathrm{C}\right]$ sucrose and are expressed as mean \pm S.E.M, $n=4$ passages $(\mathrm{p} 30 \times 2, \mathrm{p} 31$ and $\mathrm{p} 34$ for MATE1 inhibitor falmotidine at $1 \mu M$ and $n=3$ passages for MATE1 inhibitor falmotidine at $2 \mu \mathrm{M}$ ) with 6 replicates (wells) per timepoint per plate (5 time-points)

found for $\left[{ }^{14} \mathrm{C}\right]$ sucrose between the treatments (Additional file 1: Figure S10).

ATP was depleted from both cell lines to determine the role of $\mathrm{ABC}$ transporters in the efflux of haloperidol. ATP depletion did not affect the accumulation of haloperidol in either cell line (Additional file 1: Figure S11). No significant differences were observed for $\left[{ }^{14} \mathrm{C}\right]$ sucrose between the treatments (Additional file 1: Figure S11). The hypothesis that haloperidol uptake is by OCT transporters was investigated by incubating the cells with OCT1 and 2 substrate amantadine $(500 \mu \mathrm{M})$ and OCT1 and 3 substrate prazosin $(100 \mu \mathrm{M})$. $\left[{ }^{3} \mathrm{H}\right]$ haloperidol accumulation significantly decreased in the presence of amantadine in both cell lines compared to control-by $89 \%$ in
hCMEC/D3 cells and by $82 \%$ in bEnd. 3 cells and in the presence of prazosin-by $85 \%$ in hCMEC/D3 cells and by $82 \%$ in bEnd.3 cells (**** $\mathrm{p}<0.001$ ) (Additional file 1: Figure S12). No significant differences were found for $\left[{ }^{14} \mathrm{C}\right]$ sucrose between the treatments (Additional file 1: Figure S12).

The effects of other cationic drugs-unlabeled pentamidine $(100 \mu \mathrm{M})$, unlabeled efornithine $(250 \mu \mathrm{M})$ and unlabelled amisulpride $(20 \mu \mathrm{M})$ on radiolabelled haloperidol accumulation in hCMEC/D3 was investigated. Unlabelled pentamidine significantly reduced the accumulation of radiolabeled haloperidol in the cell lines after $2 \mathrm{~h}-$ by $31 \%$ in hCMEC/D3 cells (***; $<<0.001,{ }^{* *} \mathrm{p}<0.01$, and $\left.{ }^{*} \mathrm{p}<0.05\right)$. Unlabelled eflornithine significantly 
decreased the accumulation of radiolabelled haloperidol by $11 \%$ in hCMEC/D3 cells $(* * * \mathrm{p}<0.001)$. Unlabelled amisulpride $(20 \mu \mathrm{M})$ significantly decreased the accumulation of radiolabelled haloperidol in hCMEC/D3 cells-by $27 \%$ after $2 \mathrm{~h}(* * * \mathrm{p}<0.001)$ (Additional file 1: Figure S13). No significant differences were found for $\left[{ }^{14} \mathrm{C}\right]$ sucrose between the treatments (Additional file 1: Figure S13).

\section{Cytotoxicity}

No cytotoxic effects of amisulpride $(0.1-20 \mu \mathrm{M}), 1 \mu \mathrm{M}$ famotidine, $2 \mu \mathrm{M}$ famotidine, $2 \mu \mathrm{M}$ lopinavir, $20 \mu \mathrm{M}$ ergothioneine, $5 \mu \mathrm{M}$ L-carnitine, $3 \mu \mathrm{M}$ nifekalant hydrochloride and $1.5 \mu \mathrm{M}\left[{ }^{14} \mathrm{C}\right]$ sucrose (Additional file 1: Figure S14A and B) and eflornithine $(250-500 \mu \mathrm{M})$ were detected using the MTT assay (data not shown). A marker molecule $\left(\left[{ }^{14} \mathrm{C}\right]\right.$ sucrose $)$ of extracellular/vascular space was included in all $\left[{ }^{3} \mathrm{H}\right]$ amisulpride accumulation experiments and ensured that any measured effect on $\left[{ }^{3} \mathrm{H}\right]$ amisulpride values could be interpreted correctly and was not simply due to loss of membrane integrity caused by the cytotoxic nature of the drugs/inhibitors utilized.

\section{Lipophilicity}

The octanol-saline partition coefficient for $\left[{ }^{3} \mathrm{H}\right]$ amisulpride was determined to be $0.0422 \pm 0.0045$ and for $\left[{ }^{3} \mathrm{H}\right]$ haloperidol was determined to be $0.6678 \pm 0.1278$.

\section{Molecular docking studies with the SLC transporters- OCT1, MATE1 and PMAT}

Amisulpride showed molecular interactions inside the binding site of OCT1 in the form of hydrogen bonds with amino acids Gln283, Asn288, Glu380 and Asn415 as well as hydrophobic interactions with amino acid residues Phe26 and Pro385 (Fig. 5a), while haloperidol showed hydrogen bonds with amino acids Gln 283, Gly384,

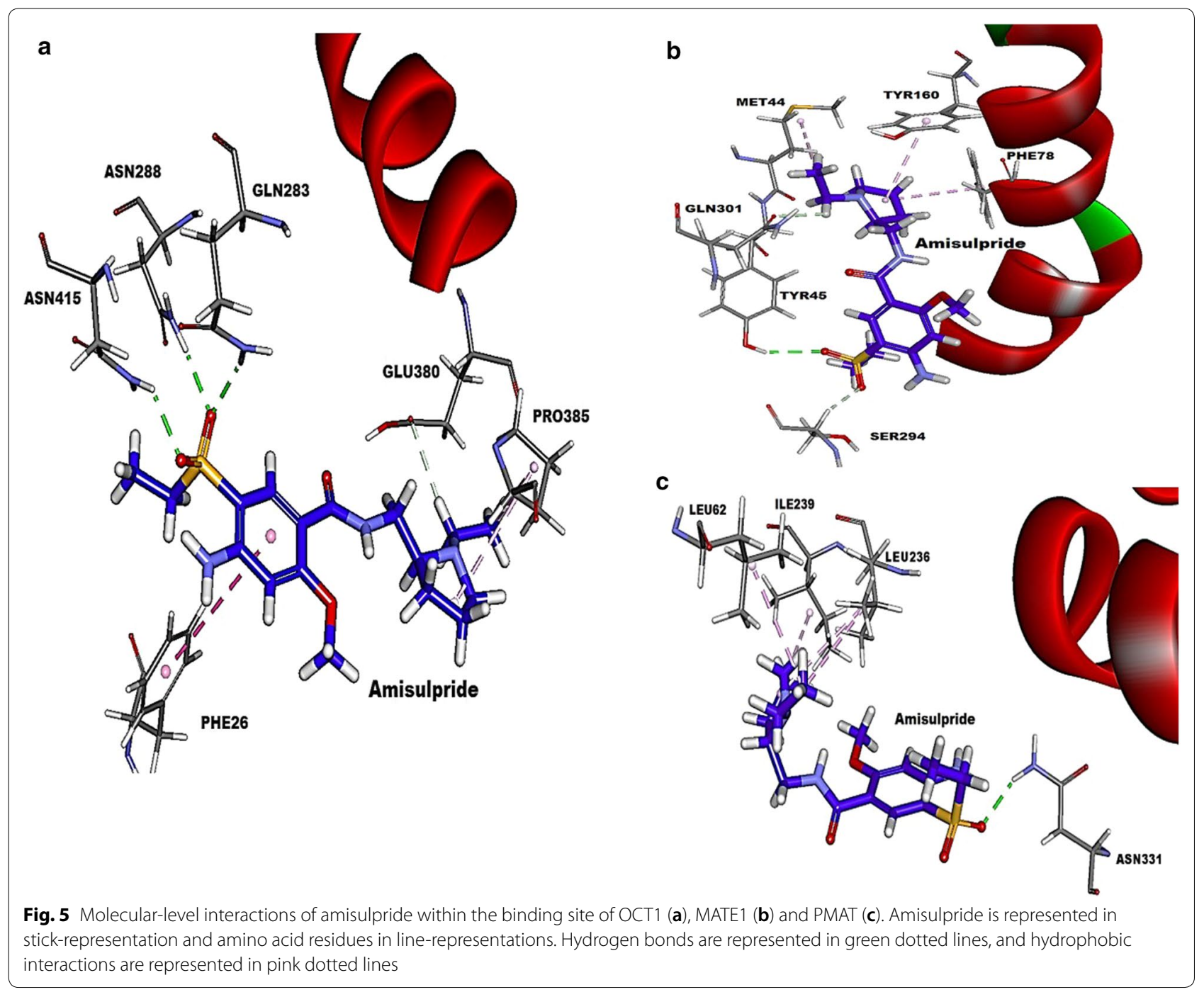


Trp388 and hydrophobic interactions with Gly384 and Pro385 while prazosin interacted with Asn288, Thr321, Ser324, Glu380, Asn411 through hydrogen bonds and hydrophobic interactions with Leu325, Val328, Gly384 and Pro385 (Additional file 1: Figure S15A). The best pose of amisulpride interacted with the binding pocket of OCT1 with a free energy of binding of $-14.28 \mathrm{kcal} / \mathrm{mol}$ while the free energy of binding for haloperidol and prazosin were $-29.97 \mathrm{kcal} / \mathrm{mol}$ and $-27.57 \mathrm{kcal} / \mathrm{mol}$.

Amisulpride showed a similar level of interaction with MATE1 transporter with a free energy of binding of $-14.32 \mathrm{kcal} / \mathrm{mol}$. It fit snugly within the binding pocket (Fig. 5b) and formed hydrogen bonds with amino acids Tyr45, Ser294 and Gln301 as well as hydrophobic interactions with amino acid residues Met44, Phe78 and Tyr160. The hydrophobic interactions appeared to play an important role in its interaction with MATE1 compared to its interaction with OCT1. The interaction of amisulpride was relatively weaker with PMAT compared to both OCT1 and MATE1 with free energy of binding $-11.4 \mathrm{kcal} / \mathrm{mol}$. It formed a single hydrogen bond with Asn331 and interacted with hydrophobic interactions with amino acid residues Leu62, Leu236 and Ile239 through hydrophobic interactions (Fig. 5c).

A similar molecular docking study suggested haloperidol is a better substrate of both MATE1 and PMAT compared to amisulpride as it showed binding affinity of binding $-22.27 \mathrm{kcal} / \mathrm{mol}$ and $-21.72 \mathrm{kcal} / \mathrm{mol}$ for MATE1 and PMAT, respectively, which are notably higher than amisulpride (Fig. 5 and Additional file 1: Figure S16). It showed good interaction with MATE1 with hydrogen bonds with Tyr45 and Ser74 and hydrophobic interaction with Phe82 and Ala67 (Additional file 1:
Figure S16A). However, the interaction of haloperidol with PMAT was limited to single hydrogen bond with Asp34 and hydrophobic interaction with Leu62 (Additional file 1: Figure S16B).

\section{Molecular docking studies with the $\mathrm{ABC}$ transporter-P-gp} The molecular docking study revealed that amisulpride was not a substrate for P-gp with a free energy binding of $-1.81 \mathrm{kcal} / \mathrm{mol}$ and the molecule was not able to interact favourably with the binding pocket of P-gp. P-gp substrates, dexamethasone and colchicine, showed notably superior interaction with P-gp with free energy of binding values of $-31.83 \mathrm{kcal} / \mathrm{mol}$ and $-16.07 \mathrm{kcal} / \mathrm{mol}$. Both dexamethasone and colchicine interacted with the binding pocket employing hydrogen bonds and hydrophobic interactions (Additional file 1: Figure S17 and Table S4).

\section{CNS amisulpride delivery in vivo}

The $\mathrm{R}_{\text {TISSUE }}$ values for $\left[{ }^{3} \mathrm{H}\right]$ amisulpride did not differ from the $\mathrm{R}_{\text {TISSUE }}$ values for $\left[{ }^{14} \mathrm{C}\right]$ sucrose in wildtype mice in all the age groups tested (Additional file 1: Table S5). There was also no effect of ageing on the brain distribution of $\left[{ }^{3} \mathrm{H}\right]$ amisulpride or $\left[{ }^{14} \mathrm{C}\right]$ sucrose. No differences were observed in the $\left[{ }^{14} \mathrm{C}\right]$ sucrose $\mathrm{R}_{\text {TISSUE }}$ values in the frontal and occipital cortex between the wildtype and transgenic mice (Fig. 6). However, in transgenic mice the $R_{\text {TISSUE }}$ value for $\left[{ }^{3} \mathrm{H}\right]$ amisulpride was significantly higher than $\left[{ }^{14} \mathrm{C}\right]$ sucrose in the frontal cortex, but not the occipital cortex. Importantly, in transgenic mice the sucrose-corrected $\mathrm{R}_{\text {TISSUE }}$ value for $\left[{ }^{3} \mathrm{H}\right.$ ] amisulpride was significantly higher than that of wildtype mice in the frontal cortex, but not the occipital cortex (Fig. 6).

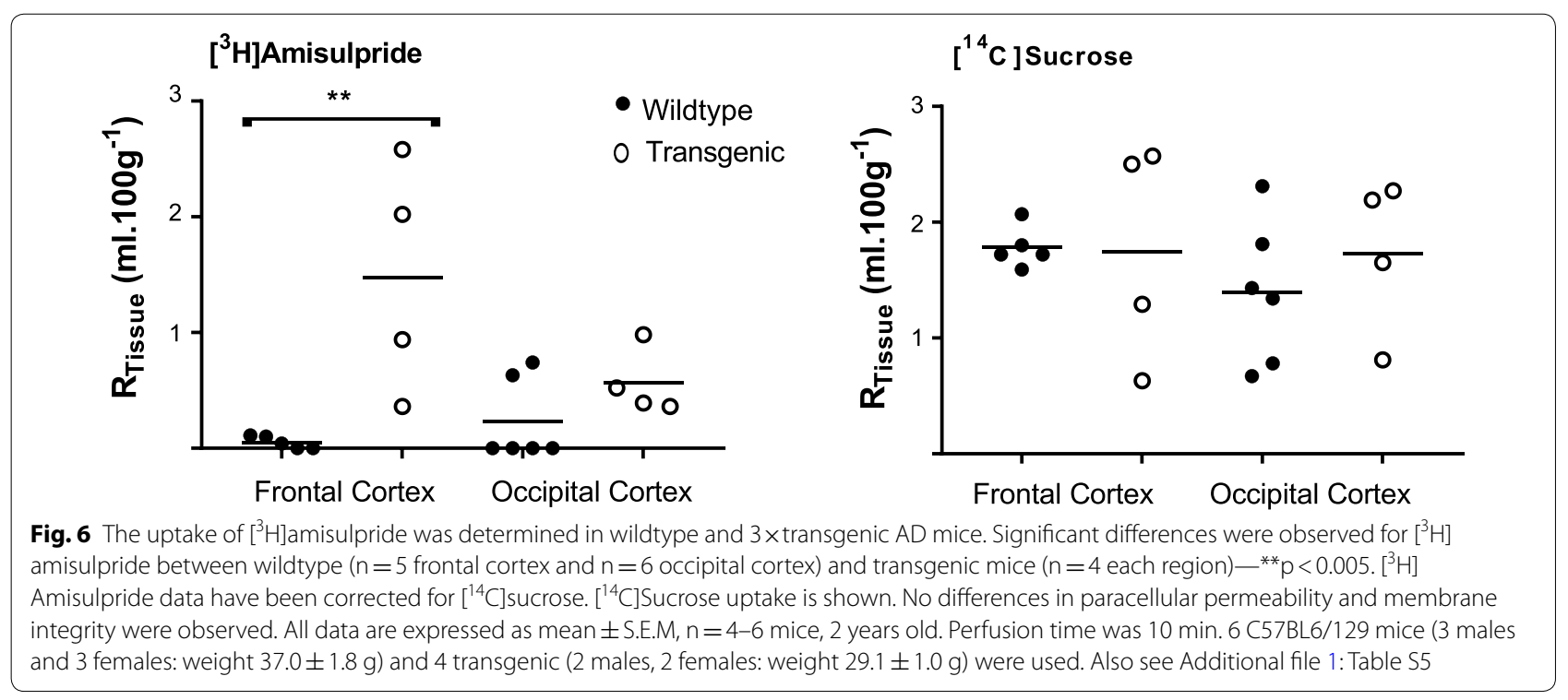




\section{Endothelial transporter expression}

\section{Cell lines}

OCTN1, OCTN2, MATE1 and MATE2 expression was confirmed in hCMEC/D3 (passages 28 and 33) and bEnd.3 (passages 18, 19 and 23) cells (Additional file 1: Figures S18 and S19A). PMAT was expressed in hCMEC/ D3 cells (passages 28, 31 and 32) and bEnd.3 (passages 17, 18, 20 and 24) (Additional file 1: Figure S19B and C).

\section{Wildtype and transgenic AD mice}

The total protein concentration measured in wildtype mice $(188.2 \pm 12.8 \mu \mathrm{g} / 100 \mu \mathrm{l})$ was not significantly different to that measured in $3 \times \mathrm{Tg} \mathrm{AD}$ mice $(195.6 \pm 13.3 \mu \mathrm{g} / 100 \mu \mathrm{l})$ brains, but this may be attributed to the fact that it was not possible to assess regional differences in these small samples. Although slight variability was observed, there was no significant differences in individual transporter (P-gp, OCT1, OCT2, OCT3, OCTN1, OCTN2, MATE1, MATE2 and PMAT) expression between the wildtype and $3 \times \mathrm{TgAD}$ mice (Additional file 1: Figures S20 and S21). Note mice were 24 months old except for MATE1 and PMAT studies where the mice were 16 and 12 months old. Data not shown for P-gp, OCT1, OCT2, OCT3 and PMAT. The expression of all these BBB transporters suggests that a capillary enriched sample had been assessed.

\section{Human brain}

Human brain capillaries were isolated from the frontal cortex (for comparison with in situ perfusion experiments), caudate nucleus and the putamen (forming the striatum where high D2 and D3 receptor occupancy is observed in individuals with AD with amisulpride usage) of healthy controls and age-matched AD affected individuals (Additional file 1: Tables S2 and S3). The total protein concentration in the capillaries was found to be significantly lower in the caudate nucleus (by $37.4 \%$ ) and putamen (by $32.5 \%$ ), but not the frontal cortex samples, from individuals with AD compared to healthy controls (Additional file 1: Table S6).

Individual transporter expression in each brain region between $\mathrm{AD}$ and healthy cases is comparable as the same amount of protein has been loaded into each well. Note this amount was dependent on the antibody utilized so was variable. Transporter expression in the frontal cortex was less variable between healthy and $\mathrm{AD}$ cases than in the other regions studied with no significant differences in transporter expression being observed (Additional file 1: Figures S22-S28; Fig. 7). Expression of OCT1 did not change between control and individuals with $\mathrm{AD}$ in all the regions tested (Additional file 1: Figures S22, S23). PMAT and MATE1 expression was significantly lower in individuals with AD in the caudate nucleus (56.2\%; $\mathrm{p}<0.05)$ and putamen $(74.8 \% ; \mathrm{p}<0.05)$ samples, respectively, compared to control (Fig. 7; Student's t-test). No other significant differences were observed, however, further cases are required to explore this more fully. Please note it is also likely that transporter expression in caudate nucleus and putamen $\mathrm{AD}$ samples is even lower than the heathy controls shown here (Fig. 7; Additional file 1: Figures S22-S28) as total protein expression is significantly reduced (Additional file 1: Table S6). The expression of all these BBB transporters would also indicate that a capillary enriched sample had been assessed.

\section{Medication history of the cases}

Additional file 1: Table S3 shows the medication history of the cases that have been used in this study. Sedatives, antidepressants and antipsychotic drugs (including haloperidol) were identified and listed together. A separate column lists all other medications.

\section{Discussion}

This study aimed to answer an important clinical question using an integrative approach to investigate the interaction between two drugs and $\mathrm{BBB}$ transporters and their potential pharmacodynamic relevance in $\mathrm{AD}$. The in vitro cell culture models and in silico computational model allowed us to [1] identify the transporters, [2] assess the potential mechanisms of amisulpride and haloperidol transport [3] perform studies on human and mouse brain endothelium and [4] minimize animal studies in line with the 3Rs (replacement, refinement and reduction principles). The in situ brain perfusion technique allowed us to [1] study the whole animal [2] and utilize a mouse model of AD. Importantly this is the only model to exhibit both amyloid- $\beta_{40}$ and ${ }_{42}$ and tau pathology, mimicking human $\mathrm{AD}[39,43]$. Both plaque and tangle pathology are mainly restricted to the hippocampus, amygdala and cerebral cortex. Transporter expression in capillaries isolated from AD and age-matched human cases and mouse brain were also assessed. Medication history of the cases was evaluated.

Cell culture studies revealed a slow accumulation of $\left[{ }^{3} \mathrm{H}\right]$ amisulpride indicating a low BBB permeability. This can be linked to its low lipophilicity, as measured by the octanol-saline partition coefficient, and its inability to interact strongly with neutral and negatively charged lipid model systems thus its limited ability to passively diffuse across the lipid bilayer [22, 44]. Please note the plasma half-life of a single oral dose of amisulpride (50 or $200 \mathrm{mg}$ ) is $\sim 12 \mathrm{~h}$, which suggests that amisulpride will not have significantly degraded within the $2 \mathrm{~h}$ incubation period used in our study [45]. Furthermore the accumulation buffer does not contain plasma enzymes which would further increase the 

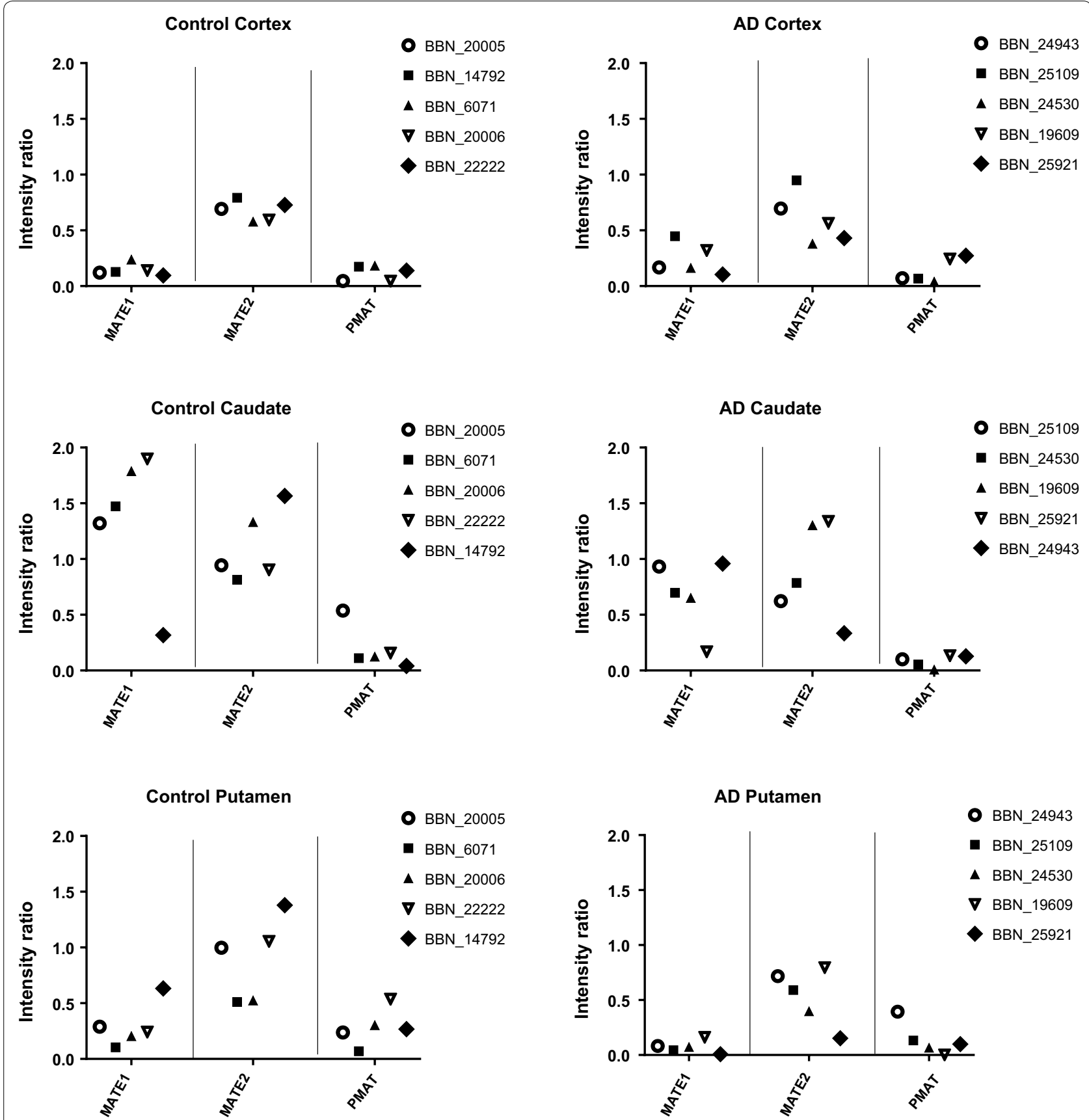

Fig. 7 Individual values have been plotted for the transporter expression in the capillaries of frontal cortex, caudate nucleus and caudate putamen samples from healthy and AD affected individuals. The numbers in the key indicate the MRC ID designated to each sample. Details of the samples can be found in Additional file 1: Tables S2 and S6

half-life of amisulpride in our cell culture models. Unlabelled amisulpride $(20 \mu \mathrm{M})$ significantly reduced $\left[{ }^{3} \mathrm{H}\right]$ amisulpride accumulation in both cell lines, suggesting that there is a low affinity influx transporter at the plasma membrane or possibly at an intracellular organelle membrane (e.g. lysozyme) [46]. OCT1, OCT2 and 3 have been shown to be expressed in hCMEC/ D3 and b.End3 cells in an earlier study by our group [32] and OCTN1 and OCTN2 were shown to be expressed in both cell lines in this present study. However, a study by Ohtsuki and colleagues found that the 
protein expression of OCT1, OCT2, OCT3, OCTN1 and OCTN2 were below detectable limits in hCMEC/ D3 cells [47].

In line with the findings of [14] and our molecular docking studies, our accumulation studies suggested that OCT1 may be the influx transporter involved, as prazosin (substrate for OCT1 and 3) reduced $\left[{ }^{3} \mathrm{H}\right]$ amisulpride uptake in hCMEC/D3 cells after $2 \mathrm{~h}$, whereas corticosterone (OCT3 substrate) had no impact on $\left[{ }^{3} \mathrm{H}\right]$ amisulpride accumulation in either cell line. In addition, OCTN1 and 2 inhibitors did not affect accumulation of $\left[{ }^{3} \mathrm{H}\right]$ amisulpride into hCMEC/D3 or bEnd.3 cells. However, in the presence of amantadine, a substrate for several transporters of organic cations (OCT1, OCT2 [48]), MATE 1, MATE 2 [49, 50] and PMAT [51]) there was no effect on hCMEC/D3 cells, and an increase in $\left[{ }^{3} \mathrm{H}\right]$ amisulpride accumulation in bEnd. 3 cells after $2 \mathrm{~h}$ incubation, which suggests the involvement of an efflux transporter. This is consistent with previous observations [22], which found higher amisulpride transport in the basolateral to apical direction (Pe $5.2 \pm 3.6 \times 10^{-6} \mathrm{~cm} / \mathrm{s}$ ) compared to the apical to basolateral direction $\left(\mathrm{Pe}<10^{-7} \mathrm{~cm} / \mathrm{s}\right)$ in porcine brain microvessel endothelium. The differences in the effect of inhibitors on the two cell lines may be explained by amisulpride being a substrate for multiple transporters and variations in the function/expression of OCT1, MATE and PMAT transporters possibly related to species differences $[52,53]$. The absence of any effect of prazosin on $\left[{ }^{3} \mathrm{H}\right]$ amisulpride uptake in bEnd. 3 cells can be explained by prazosin-associated toxicity in this cell line, which causes protein values to decrease over the course of the experiment, resulting in no net effect on $V_{D}$ values [32]. It is unlikely that the efflux transporter identified in our in vitro study is an $\mathrm{ABC}$ transporter, as neither ATP-depletion or substrates for P-gp, BCRP, or the MRP family had an effect on $\left[{ }^{3} \mathrm{H}\right]$ amisulpride accumulation in either cell line. Another study also revealed that amisulpride did not inhibit P-gp in an in vitro efflux assay [23], although they also utilised P-gp knockout and WT mice and these in vivo distribution studies suggested it was a P-gp substrate. Interestingly they considered that this may have little therapeutic impact due to its unusual receptor profile. Our single transporter computational studies revealed that amisulpride was not a P-gp substrate, but was a substrate for the SLC efflux transporters, PMAT and MATE1. Our in vitro hCMEC/D3 inhibitor studies with lopinavir, also indicated that amisulpride could be effluxed by PMAT. PMAT is thought to use a proton gradient to drive organic cation efflux from cells [53] and we (and others) have found that PMAT protein is expressed on human and mouse brain capillaries (Fig. 7, Additional file 1: Figures S19B, C and S28) [52-55]. PMAT mRNA has also been identified on the luminal and abluminal membrane of human, mouse and rat brain endothelial cells [53]. Other studies could not detect PMAT protein in isolated human capillaries and hCMEC/D3 cells $[47,56]$.

Interestingly our in vitro studies with the MATE1 inhibitor, famotidine, did not support the in silico data set which indicated that amisulpride was a MATE1 substrate. It is important to highlight that the lack of MATE1 inhibitor effect may not be conclusive proof of a lack of substrate interaction with the MATE1 transporter. It may be that the transporter was not sufficiently expressed [47, $52,55,56]$, although we could detect MATE1 protein in both our two cell lines, mouse and human brain capillary samples. Other considerations are that the inhibitor may need to reach a therapeutic concentration within the cell to elicit a response as has been previously observed with MATE1 inhibitors [50], the substrate and the inhibitor may bind to different binding sites, the non-specificity of the inhibitor, and that amisulpride interacts with both influx (OCT) and other efflux (PMAT) transporters making a response difficult to detect $[26,53,57]$.

Haloperidol has been observed to have a high degree of dopamine receptor (D2) occupancy within the brain at very low doses suggesting that haloperidol is very efficient at crossing the BBB. This is in agreement with our in vitro BBB data. Please note that the half-life of haloperidol has been reported to range 14.5-36.7 h (or up to 1.5 days) after a single oral dose so will not have been metabolized significantly over our $2 \mathrm{~h}$ incubation period [58]. Haloperidol may cross the BBB by passive diffusion, as supported by the relatively high octanol-saline partition coefficient of haloperidol $(0.6678 \pm 0.1278)$ compared to amisulpride $(0.0422 \pm 0.0045)$, or may involve transporters. The use of transporters by haloperidol is confirmed by the self-inhibition studies in both hCMEC/ D3 and b.End3 cell lines. As haloperidol exists predominately $(94.8 \%)$ as a positively charged drug at physiological $\mathrm{pH}$ ( $\mathrm{pKa}$ is 8.66 ) the transporter is likely to be OCT, which is expressed at the BBB. This was confirmed in vitro using the OCT substrates, amantadine (OCT1 and 2) and prazosin (OCT1 and 3). We also investigated the involvement of $\mathrm{ABC}$ transporters in the transport of haloperidol. For this, ATP was depleted from the cells by incubating them with $10 \mathrm{mM} 2$-deoxy-D-glucose. No effects of ATP depletion were observed compared to control in either cell line suggesting that haloperidol is not a substrate for the $\mathrm{ABC}$ transporters $\mathrm{P}$-gp, $\mathrm{BCRP}$, or the MRP family at the BBB as previously observed $[59,60]$.

Radiolabelled amisulpride $(6.5 \mathrm{nM})$ was also incubated with haloperidol (OCT1 substrate and P-gp inhibitor) $[25,61]$. Radiolabeled amisulpride accumulation was not affected by haloperidol $(40 \mu \mathrm{M})$ in either cell line. This may be the result of interactions with both OCT1 and 
P-gp, although our inhibitor and in silico studies do not suggest amisulpride is a substrate for P-gp. Conversely when radiolabeled haloperidol $(10 \mathrm{nM})$ was incubated with unlabeled amisulpride $(20 \mu \mathrm{M})$ there was a significant decrease in accumulation. Overall these results may slight reflect differences in the interaction of amisulpride and haloperidol with different transporter binding sites.

Further insight into the interaction of amisulpride and haloperidol with the transporters was obtained through the in silico computational studies, where amisulpride showed binding affinities towards the binding sites of the influx transporter, OCT1, as well as the efflux transporters, MATE1 and PMAT. The binding affinities of amisulpride towards the binding sites of these transporters showed comparable energies for OCT1 and MATE1 with molecular level interactions through hydrogen bonds and hydrophobic interactions with a number of amino acids within the binding pocket. The nature of the interaction of amisulpride with OCT1 is similar to that observed for haloperidol and prazosin which are known substrates for this transporter. The binding affinity and level of interaction were slightly weaker with PMAT compared to OCT1 and MATE1, but still considerable level of interactions were observed suggesting amisulpride is a weak substrate of PMAT. Haloperidol showed comparable affinity for both MATE1 and PMAT suggesting it is a substrate for both transporters. MATE1 and PMAT are known to use a proton gradient to drive organic cation efflux from cells [53, 54, 62, 63]. MATE1, like P-gp, is thought to be expressed on the luminal membrane of the BBB, although this remains to be confirmed [64].

The in silico study supports the experimental observations and provides further evidence that amisulpride might be influxed through OCT1 and effluxed through PMAT and MATE1 but not P-gp. When amisulpride transport was investigated in vivo, a low $\mathrm{BBB}$ permeability to $\left[{ }^{3} \mathrm{H}\right]$ amisulpride was also observed in the wild-type mice and this did not change with age. Further studies in the $3 \times \mathrm{TG}$ AD mice revealed an increased CNS uptake which was not accounted for by altered $\mathrm{BBB}$ integrity or changes in vascular space in the AD model mice, as there were no differences in $\left[{ }^{14} \mathrm{C}\right]$ sucrose uptake between the two groups; and neither was it explained by non-expression of the transporters studied (P-gp, OCT1, OCT2, OCT3, OCTN1, OCTN2, MATE1, MATE2 and PMAT). However, in post-mortem human brains expression of the efflux transporter MATE1 was lower in individuals with AD compared to age-matched healthy controls in the putamen; and PMAT showed a similar trend in the caudate nucleus, but there was no change in expression levels of these transporters in the frontal cortex. Importantly it has been reported that BBB impairments stem from
AD abnormality instead of from vascular comorbidities [65]. Further evidence for regional tissue changes with AD came from our total protein measures (Additional file 1: Table S4). This may be linked to changes in the expression of other transporters such as P-gp [18] and GLUT1 [66] as well as the other SLC transporters measured in this present study. Interestingly regional differences are known to exist in the BBB transport and the intracellular distribution of antipsychotics [67]. The reduced MATE1 and PMAT expression observed in AD may therefore underpin the heightened sensitivity to amisulpride observed in the clinical population especially as together our in silico and in vitro studies suggested that amisulpride was a substrate for MATE 1 and PMAT. Several medications listed in Additional file 1: Table S3 (e.g. citalopram, metoclopramide and loratadine) have previously been identified as OCT1 inhibitors $[25,26]$. It is not yet known if they also interact with MATE1 and PMAT. One of the medications (ranitidine) is an inhibitor of both OCT1 and MATE [64].

\section{Conclusions}

This study included a detailed evaluation of transporter expression and usage at the BBB using in silico computational approaches, in vitro models and an in vivo animal model of AD as well as patient material. The datasets have provided evidence of an interaction of amisulpride and haloperidol with both influx (OCT1) and efflux (MATE1 and PMAT) transporters, which may be expressed at the luminal or abluminal membranes of the BBB and/or at an intracellular membrane. In vitro and in silico studies indicated that amisulpride was not a substrate for $A B C$ transporters including P-gp. Furthermore, the study is of key importance as the results suggest that the heightened sensitivity to amisulpride observed in older people with $\mathrm{AD}$ is possibly due to previously unreported changes in SLC transporter expression, which increase amisulpride entry into, or possibly reduce clearance from the brain. This study is also the first step in the process of characterising age and AD-specific changes in SLC transporters of organic cations. Overall our study has implications beyond amisulpride prescribing, as it suggests that dose adjustments may be required for other drugs (e.g. haloperidol) which are substrates for SLC transporters in particular MATE1 and PMAT.

\section{Supplementary information}

Supplementary information accompanies this paper at https://doi. org/10.1186/s12987-019-0158-1.

Additional file 1. Additional figures and tables. 


\begin{abstract}
Abbreviations
OCT: organic cation transporters; OCTN: organic cation transporters novel; hCMEC/D3: immortalized human cerebral microvessel endothelial cell line; MATEs: multi-drug and toxic compound extrusion proteins; PMAT: plasma membrane monoamine transporter; $3 \times \mathrm{TgAD}$ : triple transgenic AD model; FBS: foetal bovine serum; BBB: blood-brain barrier; AD: Alzheimer's disease; P-gp: P-glycoprotein; BCRP: breast cancer resistance protein; MRP: multi-drug resistance protein; RIPA: radio-immunoprecipitation assay; SLC: solute carrier; bEnd.3: mouse brain endothelial cell lines; VLOSLP: very late-onset ( $>60$ years) schizophrenia-like psychosis; NHS: national health service; MTT: 3-(4,5-dimethylthiazol-2-yl)-2,5-diphenyltetrazolium bromide; APP: amyloid precursor protein; PBS-T: PBS-TWEEN ${ }^{\circledR}$ tablets; RT: room temperature; BDR: brains for dementia research; $V_{d}$ : volume of distribution; WB: Western blot.
\end{abstract}

\section{Acknowledgements}

We would like to thank Professor I. Romero, Professor B. Weksler, and Professor P. Couraud for the hCMEC/D3 cell line provided under MTA and Dr. Manasi Nandi for advice regarding the Western blots.

\section{Authors' contributions}

GNS co-designed the study with SAT. Performed the brain perfusions (with AF). Performed MTT assay for amisulpride and eflornithine, Western blot analysis on human tissue and the bEnd. 3 and D3 cell culture studies with unlabelled amisulpride, ATP depletion, ATP-transporter and OCT inhibitors. Analysed the resulting data. Contributed to the writing of the manuscript. ALF performed the brain perfusions (with GNS). Performed Western blots for MATE1 in bEnd.3, hCMEC/D3, wild-type and 3xTg AD mice. Analysed the resulting data. STB and RL performed the cell culture studies with MATE1, MATE2, PMAT, OCTN1 and OCTN2 inhibitors with hCMECD3 and bEnd.3 respectively. Analysed the resulting data. STB also performed MTT assay with ergothionine, L-carnitine, famotidine, lopinavir, nifekalant hydrochloride and $\left[{ }^{14} \mathrm{C}\right]$ sucrose. PMAT Western blot on hCMEC/D3. Analysed the resulting data. HR performed the Western blots for OCTN1, OCTN2 and MATE2 on bEnd.3, hCMEC/D3, wild-type and 3×Tg AD mice. Also Western blot on OCTN1 and OCTN2 on human control and AD cases. Analysed the resulting data. HW provided cell culture guidance to STB and RL. DBF and KMR performed the in silico simulations, analysed the data and contributed to the writing of the manuscript. MB provided the WT and $3 \times A D$ mice. SR provided clinical insight into the project, separated the medications into the two groups and contributed to the writing of the manuscript. SAT co-designed, directed and co-ordinated the complete study, developed the concept and wrote the majority of the manuscript. Applied for human tissue through the brains for dementia research fund. Contributed to analysing the data. All authors read and approved the final manuscript.

\section{Funding}

This research was supported by the Medical Research Council (Ph.D. studentship for Ms. Sekhar Ph.D. studies MR/K500811/1), the King's College London Alzheimer's Research UK (ARUK) network centre seed fund (to Dr. Suzanne Reeves, Dr. Sarah Thomas and Ms. Gayathri Sekhar), The Edmond and Lily Safra Research Foundation (Dr. Broadstock) and a multi-user equipment grant from The Wellcome Trust (Dr. Thomas (PI), Professors Francis, McMahon, Malcangio, and Rattray 080268). Ms Fleckney is a BBSRC-CASE funded PhD student (BB/ L01534X/1). Ms. Sevda Boyanova is a Guy's and St Thomas' Charity funded MRes-Ph.D. studentship. Mr Huzefa Rupawala is on a MRC DTP Ph.D. studentship (MR/N013700/1). Dr. Suzanne Reeves is funded by the UCLH NIHR BRC.

\section{Availability of data and materials}

See Additional file 1.

\section{Ethics approval and consent to participate}

Human tissue was provided with informed consent via the brains for dementia research (BDR) and were anonymized. BDR has ethical approval granted by the national health service (NHS) health research authority (NRES Committee London-City \& East, UK: REC reference:08/H0704/128+5. IRAS project ID:120436). Tissue was received on the basis that it will be handled, stored, used and disposed of within the terms of the Human Tissue Act 2004. Specifically the human brain tissue samples were supplied by The Manchester Brain Bank, which is part of the Brains for Dementia Research programme jointly funded by Alzheimer's Research UK and Alzheimer's Society (BDR Reference: Amendment to study-BDR14 TRID 170 recipient PI: Dr. Sarah Thomas).

\section{Consent for publication}

Not applicable.

\section{Competing interests}

The authors declare that they have no competing interests.

\section{Author details}

${ }^{1}$ Faculty of Life Sciences and Medicine, School of Cancer and Pharmaceutical Sciences, King's College London, Franklin-Wilkins Building, 150 Stamford Street, Waterloo, London SE1 9NH, UK. ${ }^{2}$ Faculty of Pharmacy, Misr International University, Cairo 11431, Egypt. ${ }^{3}$ Wolfson Centre for Age-Related Diseases, King's College London, Guy's Campus, London SE1 1UL, UK. ${ }^{4}$ Maurice Wohl Clinical Neuroscience Institute, King's College London, 125 Coldharbour Lane, Camberwell, London SE5 9N, UK. ${ }^{5}$ Division of Psychiatry, Faculty of Brain Sciences, University College London, 149 Tottenham Court Road, London W1T 7NF, UK.

Received: 10 October 2019 Accepted: 2 December 2019 Published online: 17 December 2019

\section{References}

1. Ballard C, Howard R. Neuroleptic drugs in dementia: benefits and harm. Nat Rev Neurosci. 2006;7(6):492-500. https://doi.org/10.1038/nrn1926.

2. Schneider LS, Tariot PN, Dagerman KS, Davis SM, Hsiao JK, Ismail MS, et al. Effectiveness of atypical antipsychotic drugs in patients with Alzheimer's disease. N Engl J Med. 2006;355(15):1525-38. https://doi.org/10.1056/ NEJMoa061240.

3. Reeves S, McLachlan E, Bertrand J, Antonio FD, Brownings S, Nair A, et al. Therapeutic window of dopamine D2/3 receptor occupancy to treat psychosis in Alzheimer's disease. Brain. 2017;140(4):1117-27. https://doi. org/10.1093/brain/aww359.

4. Caravaggio F, Graff-Guerrero A. Is antipsychotic sensitivity in Alzheimer's disease secondary to abnormal blood-brain barrier integrity? Brain. 2017; 140(4):865-7.

5. Mauri MC, Paletta S, Maffini M, Colasanti A, Dragogna F, Di Pace C, et al. Clinical pharmacology of atypical antipsychotics. EXCLI J. 2014;13:1163.

6. Hiemke C, Baumann P, Bergemann N, Conca A, Dietmaier O, Egberts K, et al. AGNP consensus guidelines for therapeutic drug monitoring in psychiatry: update 2011. Pharmacopsychiatry. 2011;44(6):195-235.

7. Sparshatt A, Taylor D, Patel MX, Kapur S. Amisulpride-dose, plasma concentration, occupancy and response: implications for therapeutic drug monitoring. Acta Psychiatr Scand. 2009;120(6):416-28. https://doi.org/10. 1111/j.1600-0447.2009.01429.x.

8. Lako IM, van den Heuvel ER, Knegtering H, Bruggeman R, Taxis K. Estimating dopamine D2 receptor occupancy for doses of 8 antipsychotics. J Clin Psychopharmacol. 2013;33(5):675-81.

9. Schoemaker H, Claustre Y, Fage D, Rouquier L, Chergui K, Curet $\mathrm{O}$, et al. Neurochemical characteristics of amisulpride, an atypical dopamine D2/ D3 receptor antagonist with both presynaptic and limbic selectivity. J Pharmacol Exp Ther. 1997;280(1):83-97.

10. Clark-Papasavas C, Dunn JT, Greaves S, Mogg A, Gomes R, Brownings S, et al. Towards a therapeutic window of D2/3 occupancy for treatment of psychosis in Alzheimer's disease, with [18F]fallypride positron emission tomography. Int J Geriatr Psychiatry. 2014;29(10):1001-9.

11. Reeves S, Bertrand J, D'Antonio F, McLachlan E, Nair A, Brownings S, et al. A population approach to characterise amisulpride pharmacokinetics in older people and Alzheimer's disease. Psychopharmacology. 2016;233(18):3371-81. https://doi.org/10.1007/s00213-016-4379-6.

12. Reeves S, Eggleston K, Cort E, McLachlan E, Brownings S, Nair A, et al. Therapeutic D2/3 receptor occupancies and response with low amisulpride blood concentrations in very late-onset schizophrenia-like psychosis (VLOSLP). Int J Geriatr Psychiatry. 2018;33(2):396-404. https:// doi.org/10.1002/gps.4758.

13. Saidijam M, Karimi Dermani F, Sohrabi S, Patching SG. Efflux proteins at the blood-brain barrier: review and bioinformatics analysis. Xenobiotica. 2017:48:1-27. https://doi.org/10.1080/00498254.2017.1328148.

14. Dos Santos Pereira JN, Tadjerpisheh S, Abu Abed M, Saadatmand AR, Weksler B, Romero IA, et al. The poorly membrane permeable antipsychotic 
drugs amisulpride and sulpiride are substrates of the organic cation transporters from the SLC22 family. AAPS J. 2014;16(6):1247-58.

15. Natesan S, Reckless GE, Barlow KBL, Nobrega JN, Kapur S. Amisulpride the 'atypical' atypical antipsychotic - comparison to haloperidol, risperidone and clozapine. Schizophr Res. 2008;105(1-3):224-35.

16. Kania KD, Wijesuriya HC, Hladky SB, Barrand MA. Beta amyloid effects on expression of multidrug efflux transporters in brain endothelial cells. Brain Res. 2011;1418:1-11.

17. van Assema DM, Lubberink $M$, Boellaard R, Schuit RC, Windhorst $A D$, Scheltens P, Lammertsma AA, van Berckel BN. P-glycoprotein function at the blood-brain barrier: effects of age and gender. Mol Imaging Biol. 2012;14(6):771-6.

18. Vogelgesang S, Cascorbi I, Schroeder E, Pahnke J, Kroemer HK, Siegmund W, et al. Deposition of Alzheimer's beta-amyloid is inversely correlated with P-glycoprotein expression in the brains of elderly non-demented humans. Pharmacogenetics. 2002;12(7):535-41.

19. Deo AK, Borson S, Link JM, Domino K, Eary JF, Ke B, et al. Activity of P-glycoprotein, a $\beta$-amyloid transporter at the blood-brain barrier, is compromised in patients with mild alzheimer disease. J Nucl Med. 2014;55(7):1106-11.

20. Wijesuriya HC, Bullock JY, Faull RLM, Hladky SB, Barrand MA. ABC efflux transporters in brain vasculature of Alzheimer's subjects. Brain Res. 2010;1358:228-38.

21. Park R, Kook S-Y, Park J-C, Mook-Jung I. A B1-42 reduces P-glycoprotein in the blood-brain barrier through RAGE-NF-KB signaling. Cell Death Dis. 2014;5:e1299. https://doi.org/10.1038/cddis.2014.258.

22. Härtter S, Hüwel S, Lohmann T, Abou El Ela A, Langguth P, Hiemke C, et al. How does the benzamide antipsychotic amisulpride get into the brain? - an in vitro approach comparing amisulpride with clozapine. Neuropsychopharmacology. 2003;28(11):1916-22.

23. Schmitt U, Kirschbaum KM, Poller B, Kusch-Poddar M, Drewe J, Hiemke C, et al. In vitro P-glycoprotein efflux inhibition by atypical antipsychotics is in vivo nicely reflected by pharmacodynamic but less by pharmacokinetic changes. Pharmacol Biochem Behav. 2012;102(2):312-20.

24. Piazza J, Hoare T, Molinaro L, Terpstra K, Bhandari J, Selvaganapathy PR, et al. Haloperidol-loaded intranasally administered lectin functionalized poly(ethylene glycol)-block-poly(D,L)-lactic-co-glycolic acid (PEG-PLGA) nanoparticles for the treatment of schizophrenia. Eur J Pharm Biopharm. 2014;87(1):30-9.

25. Ahlin G, Karlsson J, Pedersen JM, Gustavsson L, Larsson R, Matsson P, et al. Structural requirements for drug inhibition of the liver specific human organic cation transport protein 1. J Med Chem. 2008;51(19):5932-42. https://doi.org/10.1021/jm8003152.

26. Bourdet DL. Differential substrate and inhibitory activities of ranitidine and famotidine toward human organic cation transporter 1 (hOCT1; SLC22A1), hOCT2 (SLC22A2), and hOCT3 (SLC22A3). J Pharmacol Exp Ther. 2005;315(3):1288-97. https://doi.org/10.1124/jpet.105.091223.

27. Uchida H, Mamo DC, Mulsant BH, Pollock BG, Kapur S. Increased antipsychotic sensitivity in elderly patients: evidence and mechanisms. J Clin Psychiatry. 2009;70(3):397-405.

28. Sekhar G, Reeves S, Thomas SA. Exploring the interaction of amisulpride with influx and efflux transporters expressed at the blood-brain barrier. Pharmacology. 2015;12(3):173P.

29. Boyanova S, Wang H, Reeves S, Thomas SA. The role of solute carrier transporters in the translocation of the antipsychotic amisulpride at the blood-brain barrier in Alzheimer's disease and in normal ageing. Europhysiology. 2018;248P. https://www.europhysiology2018.org/sites/defau It/files/files/Europhysiology2018_ABSTRACTS_ONLINE.pdf.

30. Weksler B, Romero I, Couraud P-O. The hCMEC/D3 cell line as a model of the human blood brain barrier. Fluids Barriers CNS. 2013;10(1):16.

31. Brown RC, Morris AP, O'Neil RG. Tight junction protein expression and barrier properties of immortalized mouse brain microvessel endothelial cells. Brain Res. 2007;1130(1):17-30.

32. Sekhar GN, Georgian AR, Sanderson L, Vizcay-Barrena G, Brown RC, Muresan $\mathrm{P}$, et al. Organic cation transporter 1 (OCT1) is involved in pentamidine transport at the human and mouse blood-brain barrier (BBB). PLoS ONE. 2017;12(3):e0173474

33. Watson CP, Pazarentzos E, Fidanboylu M, Padilla B, Brown R, Thomas SA. The transporter and permeability interactions of asymmetric dimethylarginine (ADMA) and L-arginine with the human blood-brain barrier in vitro. Brain Res. 2016;1648:232-42.
34. Watson CP, Dogruel M, Mihoreanu L, Begley DJ, Weksler BB, Couraud PO, et al. The transport of nifurtimox, an anti-trypanosomal drug, in an in vitro model of the human blood-brain barrier: evidence for involvement of breast cancer resistance protein. Brain Res. 2012;1436:111-21.

35. Poller B, Gutmann H, KrähenbühI S, Weksler B, Romero I, Couraud P-O, et al. The human brain endothelial cell line hCMEC/D3 as a human blood-brain barrier model for drug transport studies. J Neurochem. 2008;107(5):1358-68.

36. Montesano R, Pepper MS, Möhle-Steinlein U, Risau W, Wagner EF, Orci L. Increased proteolytic activity is responsible for the aberrant morphogenetic behavior of endothelial cells expressing the middle T oncogene. Cell. 1990;62(3):435-45.

37. Anthonypillai C, Gibbs JE, Thomas SA. The distribution of the anti-HIV drug, tenofovir (PMPA), into the brain, CSF and choroid plexuses. Cerebrospinal Fluid Res. 2006;3:1.

38. Alam A, Küng R, Kowal J, McLeod RA, Tremp N, Broude EV, et al. Structure of a zosuquidar and UIC2-bound human-mouse chimeric ABCB1. Proc Natl Acad Sci. 2018;115(9):E1973-82. https://doi.org/10.1073/pnas.17170 44115.

39. Oddo S, Caccamo A, Shepherd JD, Murphy MP, Golde TE, Kayed R, et al. Triple-transgenic model of Alzheimer's disease with plaques and tangles: intracellular Abeta and synaptic dysfunction. Neuron. 2003;39(3):409-21.

40. Sanderson L, Dogruel M, Rodgers J, De Koning HP, Thomas SA. Pentamidine movement across the murine blood-brain and blood-cerebrospinal fluid barriers: effect of trypanosome infection, combination therapy, P-glycoprotein, and multidrug resistance-associated protein. J Pharmacol Exp Ther. 2009;329(3):967-71.

41. Rae EA, Brown RE. The problem of genotype and sex differences in life expectancy in transgenic AD mice. Neurosci Biobehav Rev. 2015;57:238-51.

42. Sanderson L, Khan A, Thomas S. Distribution of suramin, an antitrypanosomal drug, across the blood-brain and blood-cerebrospinal fluid interfaces in wild-type and P-glycoprotein transporter-deficient mice. Antimicrob Agents Chemother. 2007;51(9):3136-46.

43. Hirata-Fukae C, Li H-F, Hoe H-S, Gray AJ, Minami SS, Hamada K, et al. Females exhibit more extensive amyloid, but not tau, pathology in an Alzheimer transgenic model. Brain Res. 2008;1216:92-103.

44. Skrobecki P, Chmielińska A, Bonarek P, Stepien P, Wisniewska-Becker A, Dziedzicka-Wasylewska M, et al. Sulpiride, amisulpride, thioridazine, and olanzapine: interaction with model membranes. Thermodynamic and structural aspects. ACS Chem Neurosci. 2017. https://doi.org/10.1021/ acschemneuro.7b00057.

45. Coukell AJ, Spencer CM, Benfield P. Amisulpride. CNS Drugs. 1996;6(3):237-56. https://doi.org/10.2165/00023210-199606030-00006.

46. Schwake M, Schröder B, Saftig P. Lysosomal membrane proteins and their central role in physiology. Traffic. 2013;14(7):739-48.

47. Ohtsuki S, Ikeda C, Uchida Y, Sakamoto Y, Miller F, Glacial F, et al. Quantitative targeted absolute proteomic analysis of transporters, receptors and junction proteins for validation of human cerebral microvascular endothelial cell line hCMEC/D3 as a human blood-brain barrier model. Mol Pharm. 2013:10(1):289-96.

48. Dickens D, Owen A, Alfirevic A, Giannoudis A, Davies A, Weksler B, et al. Lamotrigine is a substrate for OCT1 in brain endothelial cells. Biochem Pharmacol. 2012;83(6):805-14.

49. Nies AT, Koepsell H, Damme K, Schwab M. Organic cation transporters (OCTs, MATEs), in vitro and in vivo evidence for the importance in drug therapy. Handb Exp Pharmacol. 2011;201:105-67.

50. Tsuda M, Terada T, Ueba M, Sato T, Masuda S, Katsura T, et al. Involvement of human multidrug and toxin extrusion 1 in the drug interaction between cimetidine and metformin in renal epithelial cells. J Pharmaco Exp Ther. 2009;329(1):185-91.

51. Itagaki S, Ganapathy V, Ho HTB, Zhou M, Babu E, Wang J. Electrophysiological characterization of the polyspecific organic cation transporter plasma membrane monoamine transporter. Drug Metab Dispos. 2012;40(6):1138-43.

52. Shimomura K, Okura T, Kato S, Couraud P-O, Schermann J-M, Terasaki T, et al. Functional expression of a proton-coupled organic cation ( $\mathrm{H}+/ \mathrm{OC})$ antiporter in human brain capillary endothelial cell line hCMEC/D3, a human blood-brain barrier model. Fluids Barriers CNS. 2013;10(1):8.

53. Wu KC, Lu YH, Peng YH, Hsu LC, Lin CJ. Effects of lipopolysaccharide on the expression of plasma membrane monoamine transporter (PMAT) at 
the blood-brain barrier and its implications to the transport of neurotoxins. J Neurochem. 2015. https://doi.org/10.1111/jnc.13363.

54. Hiasa M, Matsumoto T, Komatsu T, Moriyama Y. Wide variety of locations for rodent MATE1, a transporter protein that mediates the final excretion step for toxic organic cations. Am J Physiol Cell Physiol. 2006;291(4):C678-86.

55. Kurosawa T, Tega Y, Higuchi K, Yamaguchi T, Nakakura T, Mochizuki T, et al. Expression and functional characterization of drug transporters in brain microvascular endothelial cells derived from human induced pluripotent stem cells. Mol Pharm. 2018;15(12):5546-55. https://doi.org/10.1021/acs. molpharmaceut.8b00697.

56. Uchida Y, Ohtsuki S, Katsukura Y, Ikeda C, Suzuki T, Kamiie J, et al. Quantitative targeted absolute proteomics of human blood? Brain barrier transporters and receptors. J Neurochem. 2011;117(2):333-45.

57. Wittwer MB, Zur AA, Khuri N, Kido Y, Kosaka A, Zhang X, et al. Discovery of potent, selective multidrug and toxin extrusion transporter 1 (MATE1, SLC47A1) inhibitors through prescription drug profiling and computational modeling. J Med Chem. 2013;56(3):781-95. https://doi. org/10.1021/jm301302s.

58. de Leon J, Diaz FJ, Wedlund P, Josiassen RC, Cooper TB, Simpson GM. Haloperidol half-life after chronic dosing. J Clin Psychopharmacol. 2004;24(6):656-60.

59. I waki K, Sakaeda T, Kakumoto M, Nakamura T, Komoto C, Okamura N, et al. Haloperidol is an inhibitor but not substrate for MDR1/P-glycoprotein. J Pharm Pharmacol. 2006;58(12):1617-22.

60. Schinkel AH, Wagenaar E, Mol CA, van Deemter L. P-glycoprotein in the blood-brain barrier of mice influences the brain penetration and pharmacological activity of many drugs. J Clin Invest. 1996;97(11):2517-24.

61. Matsson P, Pedersen JM, Norinder U, Bergström CAS, Artursson P. Identification of novel specific and general inhibitors of the three major human ATP-binding cassette transporters P-gp, BCRP and MRP2 among registered drugs. Pharm Res. 2009;26(8):1816-31.
62. André P, Saubaméa B, Cochois-Guégan V, Marie-Claire C, Cattelotte J, Smirnova M, et al. Transport of biogenic amine neurotransmitters at the mouse blood-retina and blood-brain barriers by uptake1 and uptake2. J Cereb Blood Flow Metab. 2012;32(11):1989-2001.

63. Ito S, Kusuhara H, Yokochi M, Toyoshima J, Inoue K, Yuasa H, et al. Competitive inhibition of the luminal efflux by multidrug and toxin extrusions, but not basolateral uptake by organic cation transporter 2 , is the likely mechanism underlying the pharmacokinetic drug-drug interactions caused by cimetidine in the kidney. J Pharmacol Exp Ther. 2012;340(2):393-403.

64. Staud F, Cerveny L, Ahmadimoghaddam D, Ceckova M. Multidrug and toxin extrusion proteins (MATE/SLC47); role in pharmacokinetics. Int J Biochem Cell Biol. 2013;45(9):2007-11.

65. van de Haar HJ, Burgmans S, Jansen JFA, van Osch MJP, van Buchem MA, Muller $\mathrm{M}$, et al. Blood-brain barrier leakage in patients with early Alzheimer disease. Radiology. 2016;281(2):527-35. https://doi.org/10.1148/radio 1.2016152244.

66. Horwood N, Davies DC. Immunolabelling of hippocampal microvessel glucose transporter protein is reduced in Alzheimer's disease. Virchows Arch. 1994;425(1):69-72.

67. Loryan I, Melander E, Svensson M, Payan M, König F, Jansson B, et al. Indepth neuropharmacokinetic analysis of antipsychotics based on a novel approach to estimate unbound target-site concentration in CNS regions: link to spatial receptor occupancy. Mol Psychiatry. 2016;21(11):1527-36.

\section{Publisher's Note}

Springer Nature remains neutral with regard to jurisdictional claims in published maps and institutional affiliations.
Ready to submit your research? Choose BMC and benefit from:

- fast, convenient online submission

- thorough peer review by experienced researchers in your field

- rapid publication on acceptance

- support for research data, including large and complex data types

- gold Open Access which fosters wider collaboration and increased citations

- maximum visibility for your research: over 100M website views per year

At BMC, research is always in progress.

Learn more biomedcentral.com/submissions 